\title{
STABLE ISOTOPIC STUDY OF PRECIPITATION AND SPRING DISCHARGE ON THE NEVADA TEST SITE
}

By

\author{
Neil L. Ingraham \\ Roger L. Jacobson \\ John W. Hess \\ Bradley F. Lyles
}

\section{DISCLAIMER}

This report was prepared as an account of work sponsored by an agency of the United States Government. Neither the United States Government nor any agency thereof, nor any of their employees, makes any warranty, express or implied, or assumes any legal liability or responsibility for the accuracy, completeness, or usefulness of any information, apparatus, product, or process disclosed, or represents that its use would not infringe privately owned rights. Reference herein to any specific commercial product, process, or service by trade name, trademark, manufacturer, or otherwise does not necessarily constitute or imply its endorsement, recommendation, or favoring by the United States Government or any agency thereof. The views and opinions of authors expressed herein do not necessarily state or reflect those of the United States Government or any agency thereof.

July 1990 


\section{DISCLAIMER}

This report was prepared as an account of work sponsored by an agency of the United States Government. Neither the United States Government nor any agency Thereof, nor any of their employees, makes any warranty, express or implied, or assumes any legal liability or responsibility for the accuracy, completeness, or usefulness of any information, apparatus, product, or process disclosed, or represents that its use would not infringe privately owned rights. Reference herein to any specific commercial product, process, or service by trade name, trademark, manufacturer, or otherwise does not necessarily constitute or imply its endorsement, recommendation, or favoring by the United States Government or any agency thereof. The views and opinions of authors expressed herein do not necessarily state or reflect those of the United States Government or any agency thereof. 


\section{DISCLAIMER}

Portions of this document may be illegible in electronic image products. Images are produced from the best available original document. 


\title{
STABLE ISOTOPIC STUDY OF PRECIPITATION AND SPRING DISCHARGE ON THE NEVADA TEST SITE
}

by

\author{
Neil L. Ingraham \\ Roger L. Jacobson \\ John W. Hess \\ Bradley F. Lyles
}

\begin{abstract}
Water Resources Center
Desert Research Institute

University of Nevada System

Las Vegas and Reno, Nevada
\end{abstract}

Publication \#45078

July 1990

This research was supported in part by the U.S. Department of Energy under Contract DOE-AC08-81NV10162. 


\section{ACKNOWLEDGEMENTS}

This research was supported in part by the U.S. Department of Energy under Contract DOE-AC08-81NV10162. Sample collection was performed by Bert Elliot, Kevin Sullivan, Bruce Wert, Nancy Matuska, Tom Morris, Sam Hokett, Lee Huckins, Wyn Ross, and Alan McKay of the Desert Research Institute (DRI). The stable isotopic analyses were performed by Craig Shadel (DRI). 


\section{ABSTRACT}

Precipitation was collected in southern Nevada (on the Nevada Test Site) on a semi-regular monthly basis at 14 locations for six years for stable isotopic analysis. The total elevational range of the collection sites was $1270 \mathrm{~m}$ (4165 feet) while the total geographic range was $65 \mathrm{~km}$ (40 miles). The average difference in $\delta^{18} \mathrm{O}$ of precipitation from all sites was smallest from year to year, and amounted to only 2.3 per mil, while the average difference based on location (elevation) was only 3.7 per mil. The largest difference in $\delta^{18} \mathrm{O}$ was between enriched summer and depleted winter precipitation and amounted to more than 13 per mil.

The precipitation record shows two time-based regimes. For the first three years of collection, the precipitation was highly variable with several large events and several dry periods. During the last three years of collection, the precipitation was much more even with no large events. However, there is no correlation between the variability in the amount of precipitation and the stable isotopic composition of precipitation.

In addition, the oxygen isotope composition and discharge of two springs, Whiterock Spring and Cane Spring, issuing from perched water tables, were monitored for five years in a similar time frame as for the precipitation. During the first 2.5 years of collection, the springs responded in both volume of discharge and $\delta^{18} \mathrm{O}$ to large precipitation events. However, during the last 2.5 years of collection when precipitation moderated in amounts, but not stable isotopic composition, the springs displayed not only less variation in discharge, but in stable isotopic composition as well.

Summer precipitation may be involved in groundwater recharge, since during the first three years of collection, some of the events to which the springs responded were summer events. Moreover, the average $\delta^{18} \mathrm{O}$ of winter precipitation is less than that of the spring discharge, even when the water from large summer events is absent from the spring discharge. 


\section{CONTENTS}

ACKNOWLEDGEMENTS

ABSTRACT

INTRODUCTION 1

Previous Work 1

Purpose $\quad 2$

Sample Collection $\quad 2$

Sample Analysis $\quad 4$

$\begin{array}{ll}\text { RESULTS } & 4\end{array}$

Precipitation $\quad 4$

$\begin{array}{ll}\text { Isotopic Variation } & 7\end{array}$

$\begin{array}{ll}\text { Spring Discharge } & 24\end{array}$

$\begin{array}{ll}\text { DISCUSSION } & 48\end{array}$

$\delta^{18} \mathrm{O}$ of Spring Discharge and Source Water $\quad 48$

Relationship Between Precipitation and Spring Discharge 48

Matric vs. Fracture Infiltration $\quad 50$

Seasonal Effects and the $\delta^{18} \mathrm{O}$ of Spring Discharge 52

SUMMARY AND CONCLUSIONS 52

REFERENCES $\quad 54$ 


\section{FIGURES}

1. Location Map of the Precipitation Collection Sites and Springs

Sampled for this Study.

2. Available Pairs of the Stable Isotopic Composition of Precipitation from all Collection Sites Regardless of Amount. Also shown are the LMWL $\left(\delta \mathrm{D}=6.87 \delta^{18} \mathrm{O}-6.5\right)$ and the Meteoric Water Line $\left(\delta \mathrm{D}=8 \delta^{18} \mathrm{O}+10\right.$, Craig, 1961).

3. Available Pairs of the Stable Isotopic Composition of Precipitation for Collection Site PT1 Regardless of Amount. Also shown are the Best Fit Regression Line and the Meteoric Water Line.

4. Available Pairs of the Stable Isotopic Composition of Precipitation for Collection Site PT2 Regardless of Amount. Also shown are the Best Fit Regression Line and the Meteoric Water Line.

5. Available Pairs of the Stable Isotopic Composition of Precipitation for Collection Site PT3 Regardless of Amount. Also shown are the Best Fit Regression Line and the Meteoric Water Line.

6. Available Pairs of the Stable Isotopic Composition of Precipitation for Collection Site RT1 Regardless of Amount. Also shown are the Best Fit Regression Line and the Meteoric Water Line.

7. Available Pairs of the Stable Isotopic Composition of Precipitation for Collection Site RT2 Regardless of Amount. Also shown are the Best Fit Regression Line and the Meteoric Water Line.

8. Available Pairs of the Stable Isotopic Composition of Precipitation for Collection Site RT3 Regardless of Amount. Also shown are the Best Fit Regression Line and the Meteoric Water Line.

9. Available Pairs of the Stable Isotopic Composition of Precipitation for Collection Site SB1 Regardless of Amount. Also shown are the Best Fit Regression Line and the Meteoric Water Line.

10. Available Pairs of the Stable Isotopic Composition of Precipitation for Collection Site ST1 Regardless of Amount. Also shown are the Best Fit Regression Line and the Meteoric Water Line.

11. Available Pairs of the Stable Isotopic Composition of Precipitation for Collection Site ST2 Regardless of Amount. Also shown are the Best Fit Regression Line and the Meteoric Water Line. 
12. Available Pairs of the Stable Isotopic Composition of Precipitation for Collection Site ST3 Regardless of Amount. Also shown are the Best Fit Regression Line and the Meteoric Water Line.

13. Available Pairs of the Stable Isotopic Composition of Precipitation for Collection Site ST4 Regardless of Amount. Also shown are the Best Fit Regression Line and the Meteoric Water Line.

14. Available Pairs of the Stable Isotopic Composition of Precipitation for Collection Site TT1 Regardless of Amount. Also shown are the Best Fit Regression Line and the Meteoric Water Line.

15. Available Pairs of the Stable Isotopic Composition of Precipitation for Collection Site TT2 Regardless of Amount. Also shown are the Best Fit Regression Line and the Meteoric Water Line.

16. Available Pairs of the Stable Isotopic Composition of Precipitation for Collection Site TT3 Regardless of Amount. Also shown are the Best Fit Regression Line and the Meteoric Water Line.

17. Location Map Showing the Weighted Average in $\delta^{18} \mathrm{O}$ of Precipitation at each Collection Site.

18. Location Map Showing the Weighted Average in $8 \mathrm{D}$ of Precipitation at each Collection Site.

19. Weighted Average of the Oxygen Isotopic Ratios vs. Elevation for each Collection Site.

20. Time Series of the Weighted Average of the Oxygen Isotope Composition of Precipitation from Site PT1 During the Period of Collection.

21. Time Series of the Weighted Average of the Oxygen Isotope Composition of Precipitation from Site PT2 During the Period of Collection.

22. Time Series of the Weighted Average of the Oxygen Isotope Composition of Precipitation from Site PT3 During the Period of Collection.

23. Time Series of the Weighted Average of the Oxygen Isotope Composition of Precipitation from Site RT1 During the Period of Collection. 
24. Time Series of the Weighted Average of the Oxygen Isotope Composition of Precipitation from Site RT2 During the Period of Collection.

25. Time Series of the Weighted Average of the Oxygen Isotope Composition of Precipitation from Site RT3 During the Period of Collection.

26. Time Series of the Weighted Average of the Oxygen Isotope Composition of Precipitation from Site SB1 During the Period of Collection.

27. Time Series of the Weighted Average of the Oxygen Isotope Composition of Precipitation from Site ST1 During the Period of Collection.

28. Time Series of the Weighted Average of the Oxygen Isotope Composition of Precipitation from Site ST2 During the Period of Collection.

29. Time Series of the Weighted Average of the Oxygen Isotope Composition of Precipitation from Site ST3 During the Period of Collection.

30. Time Series of the Weighted Average of the Oxygen Isotope Composition of Precipitation from Site ST4 During the Period of Collection.

31. Time Series of the Weighted Average of the Oxygen Isotope Composition of Precipitation from Site TT1 During the Period of Collection.

32. Time Series of the Weighted Average of the Oxygen Isotope Composition of Precipitation from Site TT2 During the Period of Collection.

33. Time Series of the Weighted Average of the Oxygen Isotope Composition of Precipitation from Site TT3 During the Period of Collection.

34. Weighted Average of $\delta^{18} \mathrm{O}$ in Precipitation from all Sites During the Period of Collection.

35. The Weighted Average of the $\delta^{18} \mathrm{O}$ of Precipitation for each Month from all Stations. 
36. The Total Amount of Precipitation Collected within each 0.5 per mil Interval in $\delta^{18} \mathrm{O}$. The Weighted Mean of the Oxygen Isotope Compositions of all Precipitation Samples Collected is -11.9 per mil, while the Mode is between -13.0 and -14.5 per mil.

37. Discharges (in liters/min) from Whiterock Spring and Amounts of Precipitation (in mm) Collected Nearby.

38. Discharges (in liters/min) from Cane Spring and Amounts of Precipitation (in mm) Collected Nearby.

39. The Available Stable Isotopic Pairs $\left(\delta D\right.$ and $\left.\delta^{18} O\right)$ of Discharge Water from Whiterock Spring and Cane Spring. Also shown are the Meteoric Water Line (MWL: $\delta D=8 \delta^{18} \mathrm{O}+10$; Craig, 1961) and the Local Meteoric Water Line (LMWL: $\delta \mathrm{D}=6.87 \delta^{18} \mathrm{O}-6.5$ ) of this Research. The Spring Waters Plot in Two Separate Fields and Appear to have Undergone Evaporation following an Evaporation Line as shown.

40. Time Series of the Stable Oxygen Isotope Compositions of Discharge Water from Cane and Whiterock Springs, for the Period of Collection. Both Springs show Considerable Fluctuation, but Display the Fluctuation in Unison.

41. Time Series of the Stable Oxygen Isotope Compositions of Discharge Water from Whiterock Spring (closed squares) and those of the Nearest Precipitation Collection Sites (RT2 and RT3) (open squares) over the Period of Collection. The Samples also Analyzed for Tritium are Designated with a T.

42. Time Series of the Stable Oxygen Isotope Compositions of Discharge Water from Cane Spring (closed squares) and those of the Nearest Precipitation Collection Sites (ST3 and ST4) (open squares) over the Period of Collection. The Samples also Analyzed for Tritium are Designated with a $\mathrm{T}$, while that Analyzed for ${ }^{14} \mathrm{C}$ is Designated with a $\mathrm{C}$. 


\section{TABLES}

1. The Locations of the Precipitation Sampling on the NTS.

2. The Weighted Averages of $\delta^{18} \mathrm{O}$ and $\delta \mathrm{D}$ in Precipitation and Elevation in Meters (feet) for each Sampling Location.

3. The Weighted Averages of $\delta^{18} \mathrm{O}$ in Precipitation by Year of Collection. 26 


\section{INTRODUCTION}

This is the first report of the stable isotopic composition of precipitation on the $\mathrm{Ne}$ vada Test Site (NTS) by the Desert Research Institute (DRI). The precipitation sampling network was initiated in late 1982 and was operated through 1986. The purpose was to establish baseline information on the stable isotopic composition of precipitation on and around the NTS. This information will be valuable for other studies dealing with groundwater recharge and movement, climate change, and infiltration rates, among others.

The stable isotopes of hydrogen $(\mathrm{H}$ and $\mathrm{D})$ and of oxygen $\left({ }^{16} \mathrm{O}\right.$ and $\left.{ }^{18} \mathrm{O}\right)$ are uniquely suited to studying hydrologic processes since these elements comprise the chemical entity of interest, water. Phase-change processes in nature, such as evaporation, condensation (either to liquid or solid), and sublimation, result in separation or fractionation of these isotopes among the different hydrologic components due to the effects of mass on the rates of reaction. These fractionation processes are also temperature dependent, and, therefore, the history of water is recorded in its isotopic composition, permitting in many cases the identification of water of different meteorological sources, or climates, that may be otherwise indistinguishable.

Since, for the most part, only phase changes fractionate stable isotopes among the hydrologic components, water entering the ground as infiltration will retain the isotopic signature of its source. Thus, the knowledge of the stable isotopic composition of current precipitation will aid in the determination of the sources and origins of groundwater on the NTS.

\section{Previous Work}

The light stable isotopic composition of precipitation has been used to determine the season most responsible for infiltration and groundwater recharge. By using stable isotopic ratios of precipitation, lysimeter water and groundwater, Darling and Bath (1938) were able to discern that recharge through a chalk aquifer was occurring year-round. Winograd and Riggs (1984), using isotopic data of snow, rain and springs, concluded that groundwater recharge to the Spring Mountains in southern Nevada occurs primarily from winter precipitation, and that water from summer precipitation is rarely involved in recharge. These researchers also stated that significant recharge events may be as much as five years apart. These conclusions were supported by Hershey et al. (1987) who also compared stable isotopic composition of snow and of spring discharge on the Spring Mountains. 
The stable isotopic composition of precipitation has been shown to be highly variable even in regions of single precipitation periods. Ingraham and Taylor (in prep.) found differences in deuterium contents of 40 per mil at one location during one season, whereas Smith et al. (1979) found variations of $\delta \mathrm{D}$ in precipitation of up to 37 per mil between individual storms in northern California. Milne et al. (1987) reported on three years of record on the isotopic composition of precipitation in southern Nevada. Their data show large variations as well, however, these researchers offered no interpretations or conclusions concerning the results.

Southern Nevada, as with most of the southwest, has two precipitation periods, a winter period and a summer period. Winter precipitation is produced from frontal systems migrating eastward off the Pacific Ocean and is colder than the summer precipitation. The summer rains occur primarily as localized high-intensity convective storms (French, 1983; 1985) that are a result of subtropical disturbances moving northward from the Gulf of California (Hales, 1972, 1974). Simpson et al. (1972) have demonstrated a substantial and predictable difference in the stable isotopic composition of precipitation during these two periods. The differences between the stable isotopic ratios of summer and winter precipitation result from differences in storm origin, history, temperature and degrees of evaporation during descent. The colder winter precipitation from isotopically more advanced storm systems is more isotopically depleted. The warmer summer storms produce more isotopically enriched precipitation. Thus, in order to interpret the stable isotopic results of spring discharge, especially in areas of dual precipitation periods, numerous samples of precipitation must be collected.

\section{Purpose}

The purpose of collecting precipitation was to establish baseline information on the stable isotopic composition of precipitation on the NTS. The variations in the stable isotopic ratios of precipitation are interpreted in terms of differences in location, elevation, season, and year.

In addition, two springs on the NTS, Whiterock Spring and Cane Spring, were also sampled for stable isotopic analysis during the same time period. This stable isotopic data allowed interpretations concerning the response of the springs' discharge to large precipitation events, and the precipitation period most responsible for infiltration and recharge.

\section{Sample Collection}

Precipitation was collected at 14 sites, between February 1982 and December 1986, for stable isotopic analysis. Precipitation collection sites were chosen to allow determina- 
tion of the total geographic and elevational variation in stable isotopic composition of precipitation of the NTS. Table 1 contains a brief description of the location of each sampling station.

Precipitation was collected by a simple device consisting of a catchment area of 0.22 $\mathrm{m}^{2}\left(2.4 \mathrm{ft}^{2}\right)$ placed over a barrel. The catchment area was connected to a collection vessel by a tube with a $U$-shaped trap. The U-trap was designed to remain filled with water after a precipitation event, thus protecting the water sample in the collection vessel from evaporation and associated isotopic enrichment. The barrel was then partially buried for stability.

There was no systematic timing of sample collection. Field collection was perfornned on a semi-regular basis that was designed to determine the average yearly and seasonal stable isotopic ratios of precipitation. On many occasions, sampling was performed in conjunction with other unrelated field work and sample collection for logistic purposes. The result was an arbitrary schedule of sample collection that was usually between three and six weeks. The stable isotopic composition of individual storms or any specific month, then, cannot be discerned. However, the sheer glut of samples allows confidence in the weighted averages of $\delta^{18} \mathrm{O}$ on a monthly and yearly basis, as well as location.

The two springs, Cane and Whiterock, were monitored for their stable isotopic composition as well as discharge on a schedule similar to the precipitation collection. The dis-

TABLE 1. THE LOCATIONS OF THE PRECIPITATION SAMPLING ON THE NTS.

\begin{tabular}{lllll}
\hline Station & $\begin{array}{c}\text { Elevation } \\
\text { meters feet }\end{array}$ & locns & locew & 7 1/2" Quadrangle \\
\hline PT1 & $2200(7200)$ & N920,700 & E606,800 & Ammonia Tanks \\
PT2 & $2060(6760)$ & N922,700 & E591,900 & Dead Horse Flat \\
PT3 & $1890(6200)$ & N900,200 & E561,400 & Scrugham Peak \\
RT1 & $2235(7330)$ & N893,500 & E635,000 & Rainier Mesa \\
RT2 & $1900(6230)$ & N877,000 & E630,900 & Rainier Mesa \\
RT3 & $1590(5220)$ & N866,500 & E610,200 & Ammonia Tanks \\
SB1 & $960(3160)$ & N767,000 & E709,000 & Frenchman Flat \\
ST1 & $2135(7000)$ & N799,100 & E618,800 & Topopah Spring \\
ST2 & $1830(6000)$ & N797,100 & E621,700 & Topopah Spring \\
ST3 & $1525(5000)$ & N787,700 & E617,300 & Topopah Spring \\
ST4 & $1225(4020)$ & N764,400 & E616,300 & Jackass Flats \\
TT1 & $1840(6040)$ & N840,500 & E565,100 & Timber Mtn. \\
TT2 & $1630(5340)$ & N836,900 & E582,100 & Timber Mtn. \\
TT3 & $1400(4600)$ & N836,200 & E600,300 & Buckboard Mesa \\
\hline
\end{tabular}


charges of both springs are small and, thus, the orifices have been developed by the digging of adits. The water slowly seeps out of the rock and collects in a pool in the adit before flowing out. The discharges from the adits were measured with a stopwatch and volurnetric cylinder during each visit over the five years of collection. Several tritium analyses of both springs and one ${ }^{14} \mathrm{C}$ analysis of Cane Spring were also performed. In addition, precise measurements of precipitation were obtained from rain gages located close to the springs. The locations of the precipitation collection sites and Whiterock and Cane Springs are shown in Figure 1.

\section{Sample Analysis}

All samples were collected in glass bottles and sealed with plastic tape to prevent leakage or evaporation. The oxygen isotope analyses were performed by the complete conversion of water to $\mathrm{CO}_{2}$ by guanidine hydrochloride (Dugan et al., 1985). The hydrogen isotope ratios were determined by the quantitative conversion of water to hydrogen gas using uranium as a reducing agent (Bigeleisen et al., 1952). The hydrogen and $\mathrm{CO}_{2}$ gases were then each introduced directly into mass spectrometers.

The hydrogen gas was analyzed in a Nuclide 3-60 HD double-collector mass spectrometer, while the $\mathrm{CO}_{2}$ was analyzed in a Delta E Finnigan-Matt triple-collector mass spectrometer. The reproducibility of the $\delta \mathrm{D}$ values are 1 per mil, while the $\delta^{18} \mathrm{O}$ values have a reproducibility of 0.2 per mil. All data are reported in the standard $\delta$ - notation with respect to standard mean ocean water (SMOW).

\section{RESULTS}

Over 400 precipitation samples and nearly 100 spring samples were analyzed for their oxygen isotope ratios, while about 275 of the precipitation and 70 of the spring samples were analyzed for their hydrogen isotope ratios. Therefore, the conclusions presented here are primarily based on interpretations made from the oxygen isotope ratios.

\section{Precipitation}

All of the available pairs of stable isotopic data $\left(\delta \mathrm{D}\right.$ and $\left.\delta^{18} \mathrm{O}\right)$ of precipitation are plotted in Figure 2. The data produces a regression line with the equation: $\delta \mathrm{D}=6.87$ $8^{18} \mathrm{O}-6.5$ with a correlation coefficient of 0.97 . This local meteoric water line (LMWL) represents the stable isotopic ratios of both summer and winter precipitation (regardless of amount) from all stations. This local line differs from the global meteoric water line (MWL: $\delta \mathrm{D}=8 \delta^{18} \mathrm{O}+10$, Craig, 1961); however, as shown in Figure 2, most of the data plot close to the global line as well. 


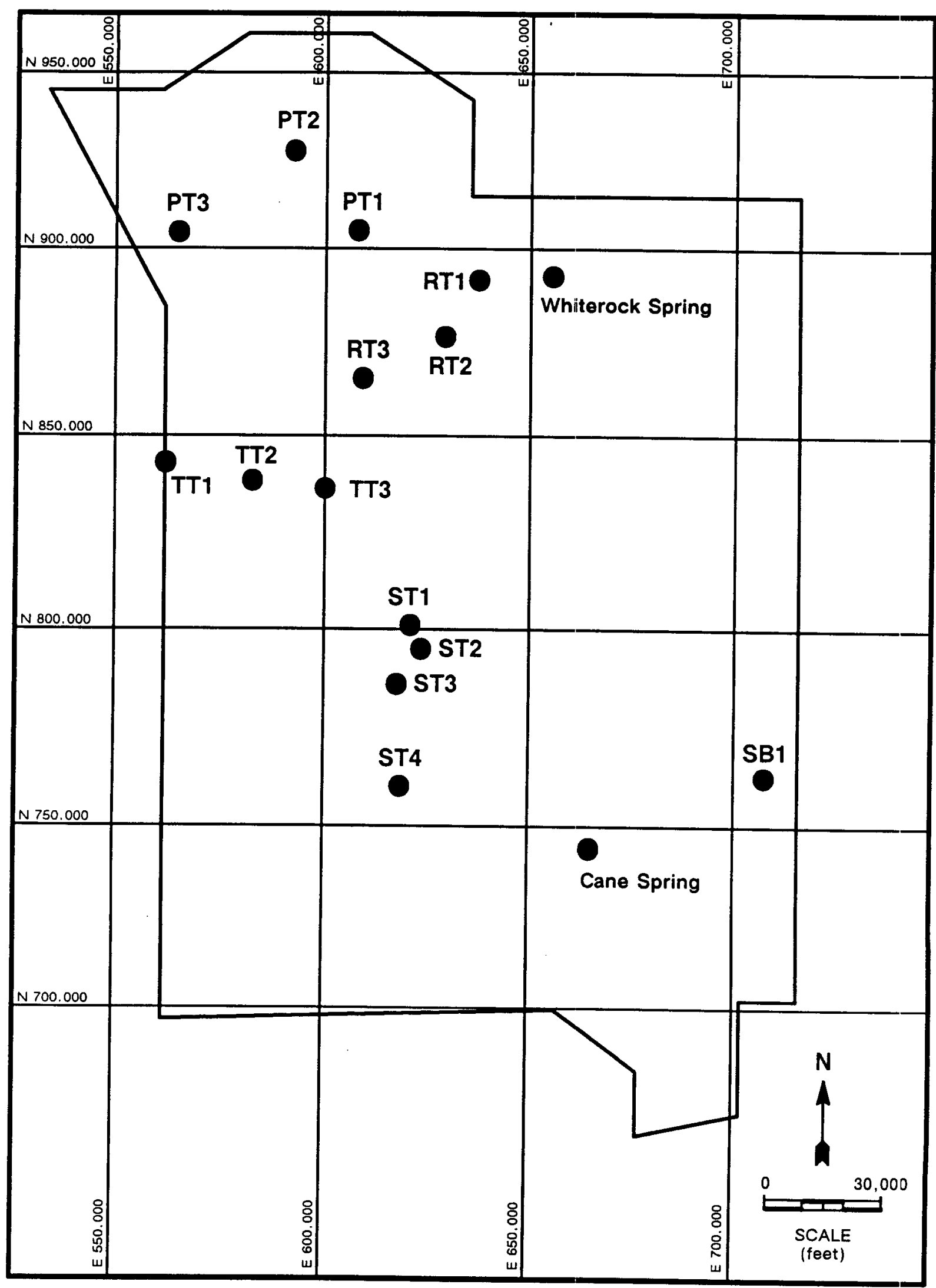

FIGURE 1. Location Map of the Precipitation Collection Sites and Springs Sampled for this Study. 


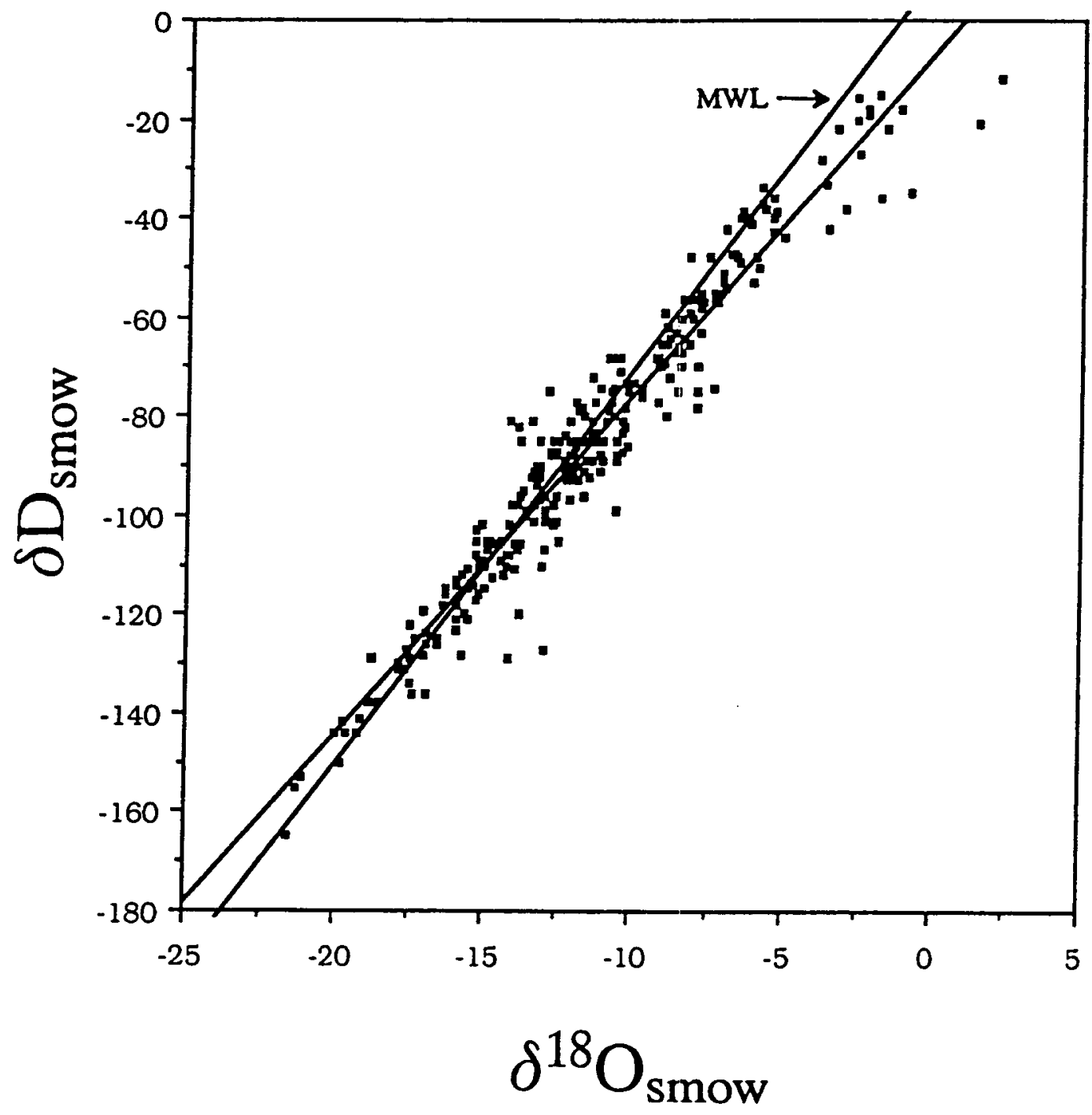

FIGURE 2. Available Pairs of the Stable Isotopic Composition of Precipitation from all Collection Sites Regardless of Amount. Also shown are the LMW/L $\left(\delta D=6.87 \delta^{18} \mathrm{O}-6.5\right)$ and the Meteoric Water Line $\left(\delta \mathrm{D}=8 \delta^{18} \mathrm{O}+10\right.$, Craig, 1961). 
All of the available pairs of stable isotopic data for each station are also plotted in Figures 3 through 16. A regression line has been calculated for each station, which is shown in the figures. The slopes range between 6.2 and 8.0, the intercepts range between -16.4 and +9.2 . All of the correlation coefficients are above 0.91 , while most are above 0.95 .

\section{Isotopic Variation}

Figures 17 and 18 show the weighted $\delta^{18} \mathrm{O}$ and $\delta \mathrm{D}$ and compositions at each site for the period of collection. All of the collection sites are located within the NTS boundaries and, thus, are in reasonably close geographic proximity. The variations in stable isotopic ratios of the precipitation as shown in Figures 17 and 18 are not thought to be geographic, but rather are limited to differences in elevation of the collection sites. The weighted average of the oxygen isotope ratios for each collection site and the elevation of the site is shown in Table 2 and Figure 19. The total difference between all sites is only 3.7 per mil.

Additional variations, however, are observed in the stable isotopic ratios of precipitation based on the time of collection. There appears to be minimal variation in the oxygen isotope ratios in precipitation from year to year. Table 3 shows the total weighted average of $\delta^{18} \mathrm{O}$ in precipitation by year for each of the five years of data. The total variation between the five years is only 2.3 per mil.

Most of the variation in the stable isotopic composition of precipitation from the NTS can be attributed to season and inter-storm variation. Figures 20 through 33 show the oxygen isotope ratios versus time of collection for each sampling location over the period of collection (1982 through 1986). Nearly every station displays a 15 per mil variation over the five-year period, while some stations display a 20 per mil variation over the period of sample collection. The variation appears to be generally limited to seasonal differences. Every station displays a seasonal variation of depleted precipitation in winter and more enriched precipitation in summer. Figure 34 shows the weighted average of the oxygen isotope ratios from all precipitation sites versus time over the period of collection (1982 through 1986). Differences as much as 15 per mil are observed over the five-year period between the depleted winter precipitation and enriched summer precipitation.

This seasonal variation is readily apparent in Figure 35, which shows the weighted average of the $\delta^{18} \mathrm{O}$ of precipitation for each month (from all stations). The $\delta^{18} \mathrm{O}$ of precipitation decreases slightly between January and March, followed by a sharp increase of nearly 11 per mil by July. However, over the five-year period, there has only been cne sampling run in July leaving the true composition of precipitation in mid-summer uncer- 


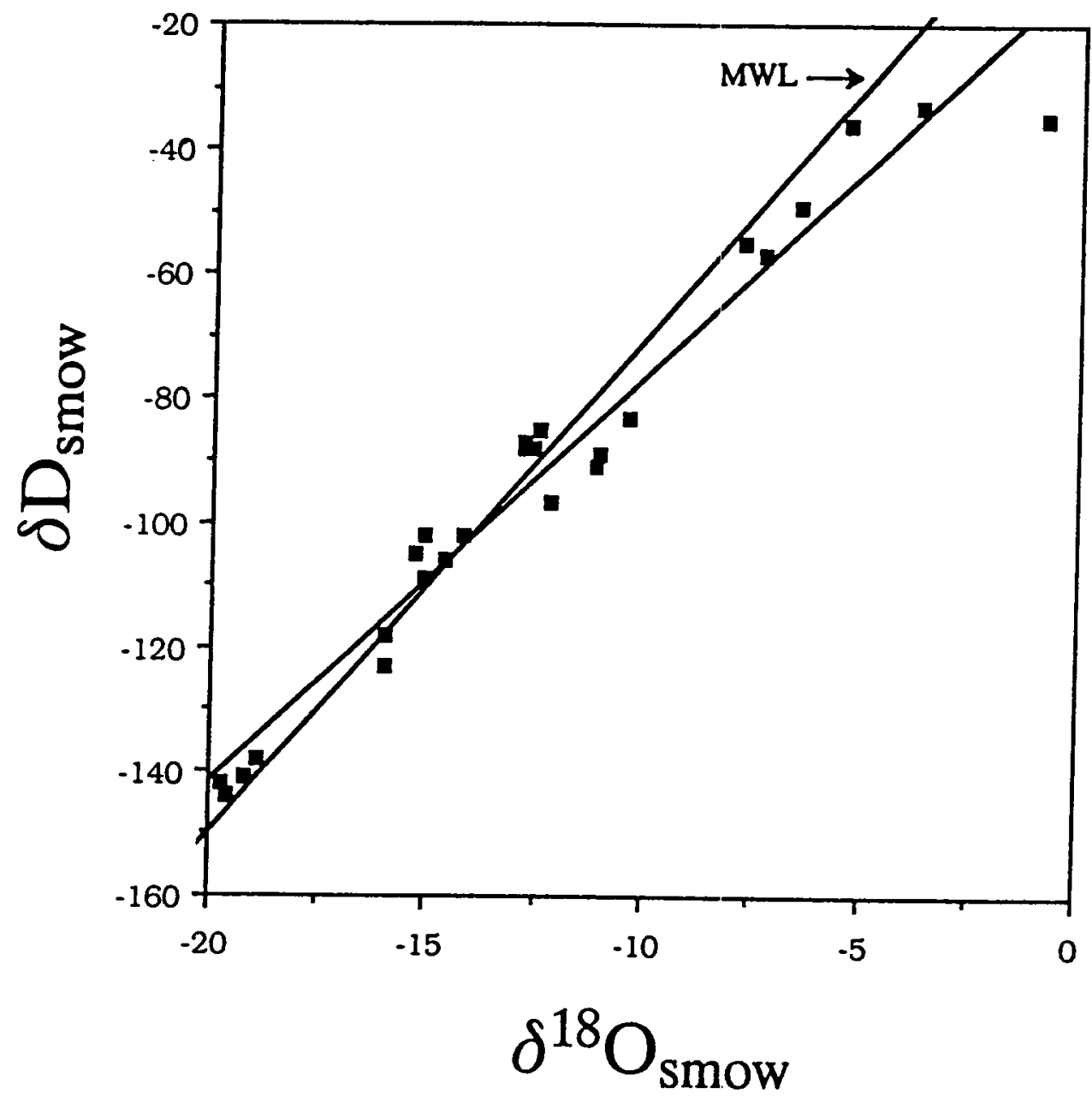

FIGURE 3. Available Pairs of the Stable Isotopic Composition of Precipitation for Collection Site PT1 Regardless of Amount. Also shown are the Best Fit Regression Line and the Meteoric Water Line. 


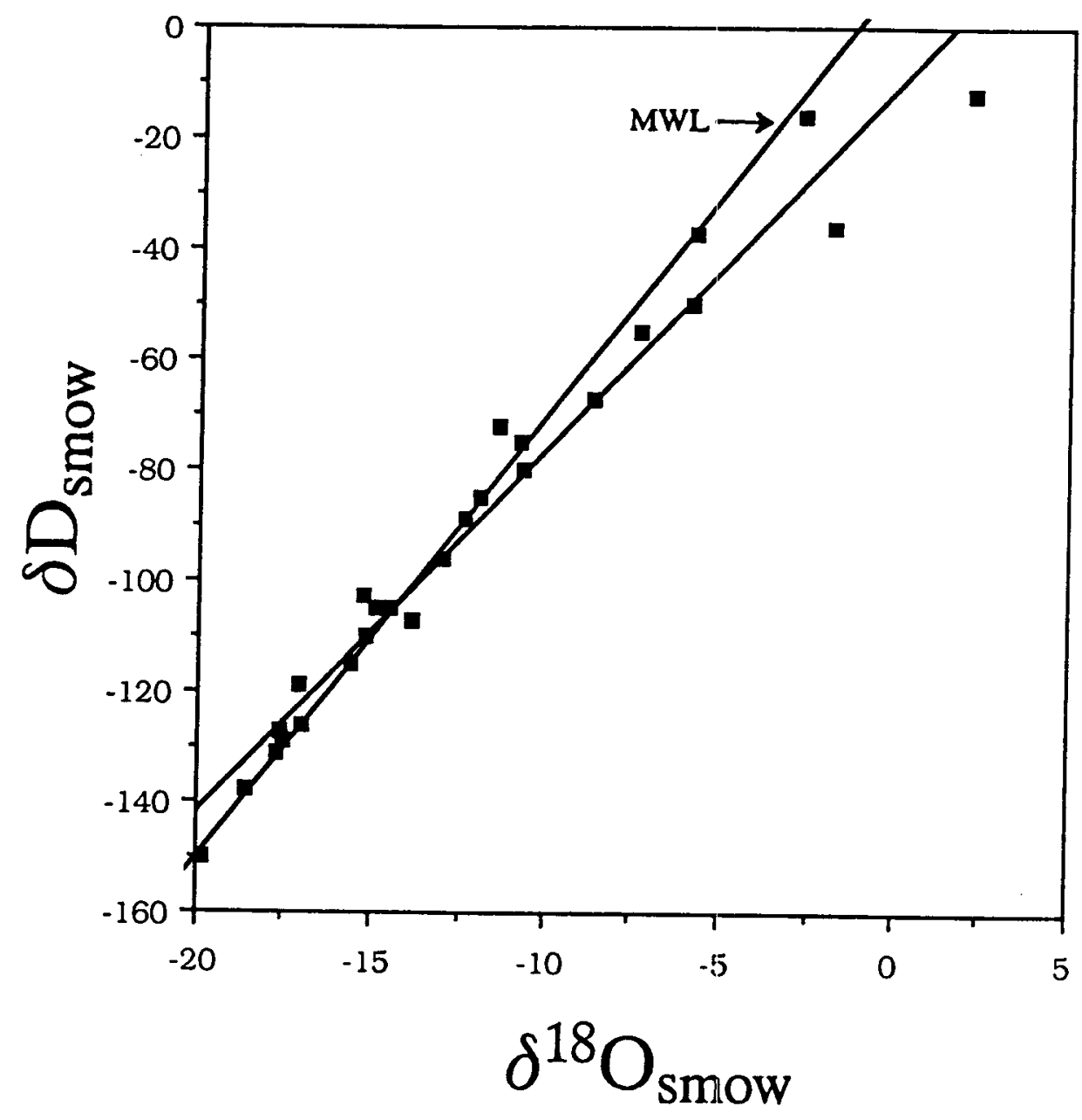

FIGURE 4. Available Pairs of the Stable Isotopic Composition of Precipitation for Collection Site PT2 Regardless of Amount. Also shown are the Best Fit Regression Line and the Meteoric Water Line. 


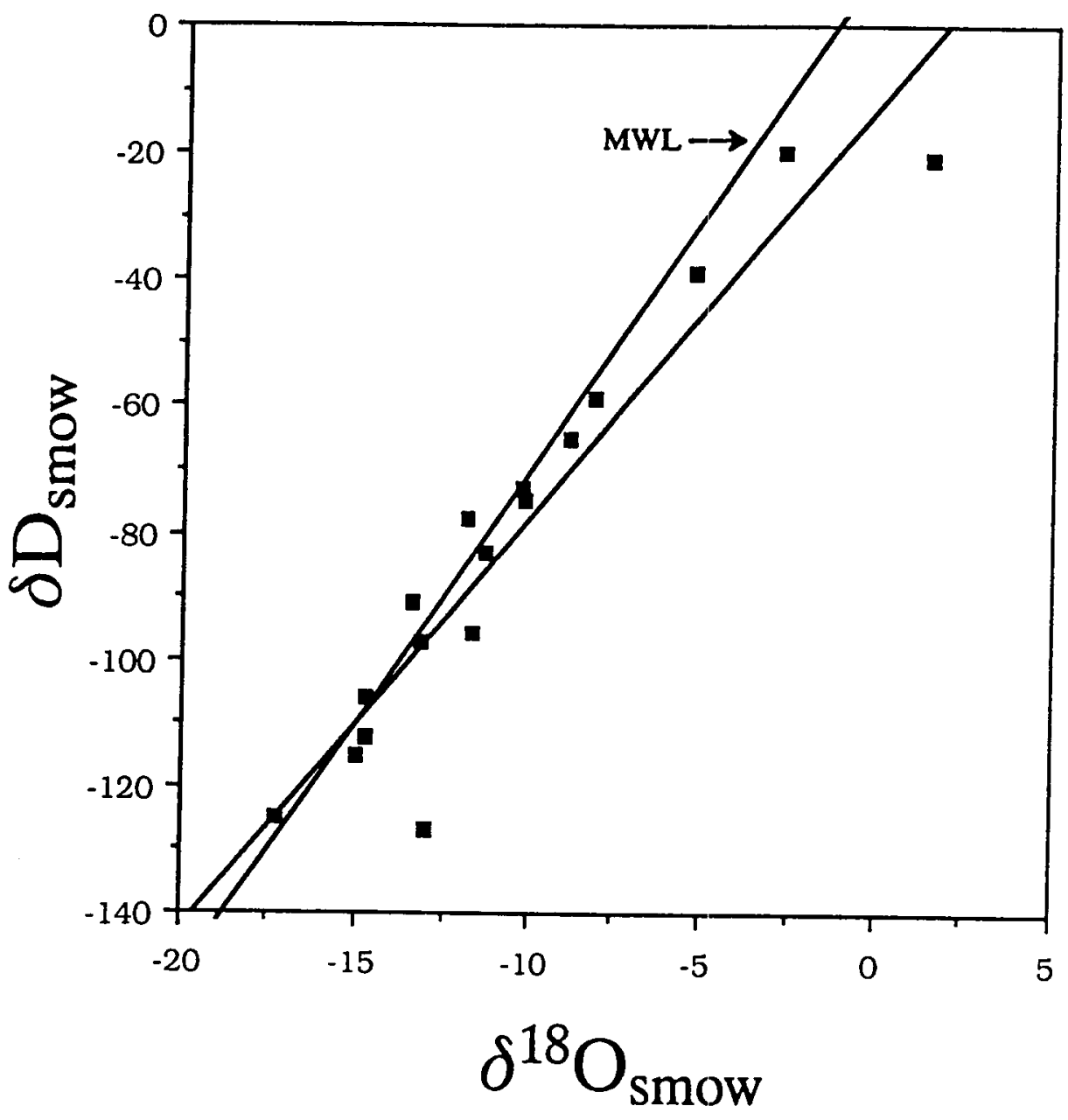

FIGURE 5. Available Pairs of the Stable Isotopic Composition of Precipitation for Collection Site PT3 Regardless of Amount. Also shown are the Best Fit Regression Line and the Meteoric Water Line. 


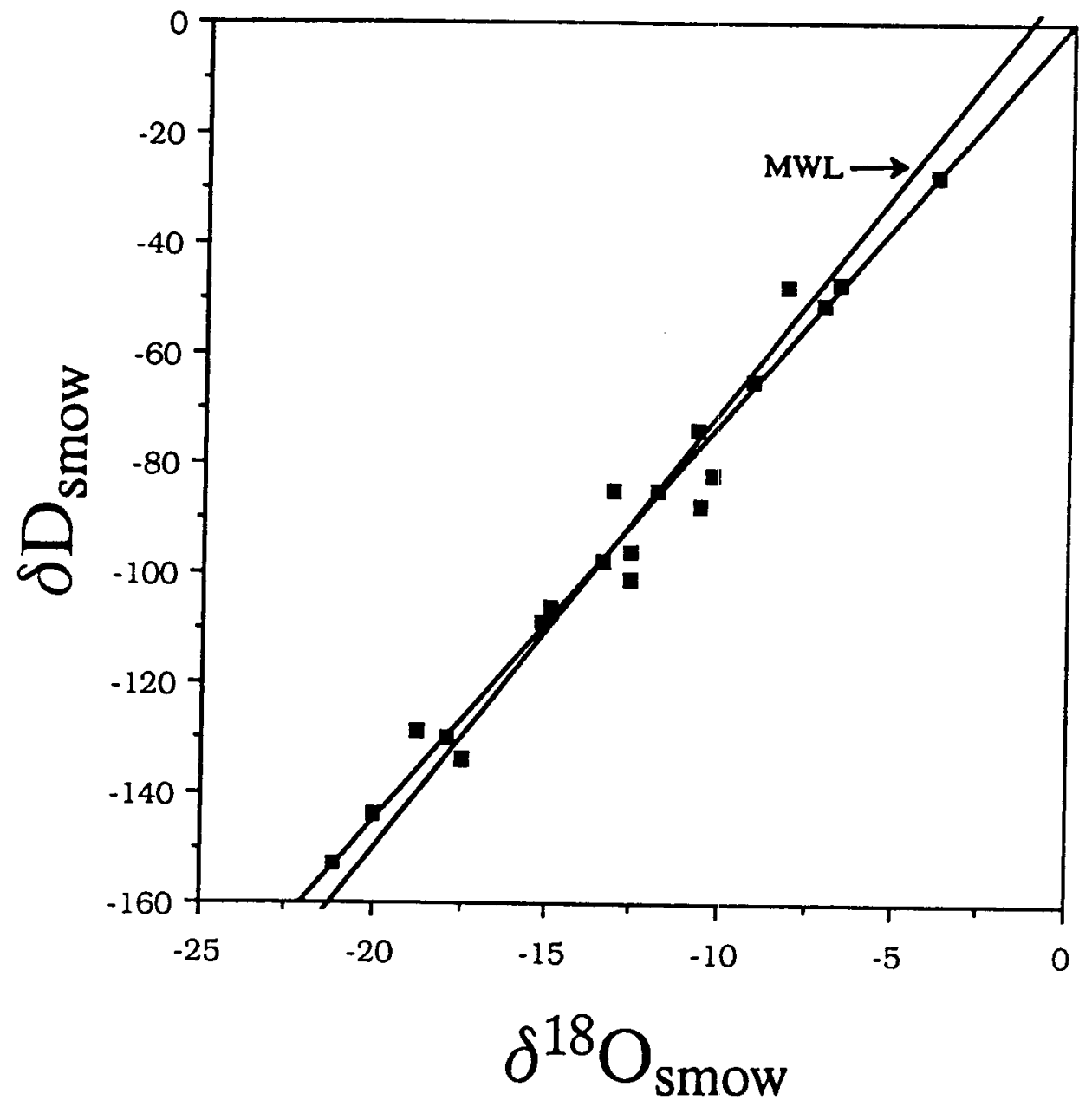

FIGURE 6. Available Pairs of the Stable Isotopic Composition of Precipitation for Collection Site RT1 Regardless of Amount. Also shown are the Best Fit Regression Line and the Meteoric Water Line. 


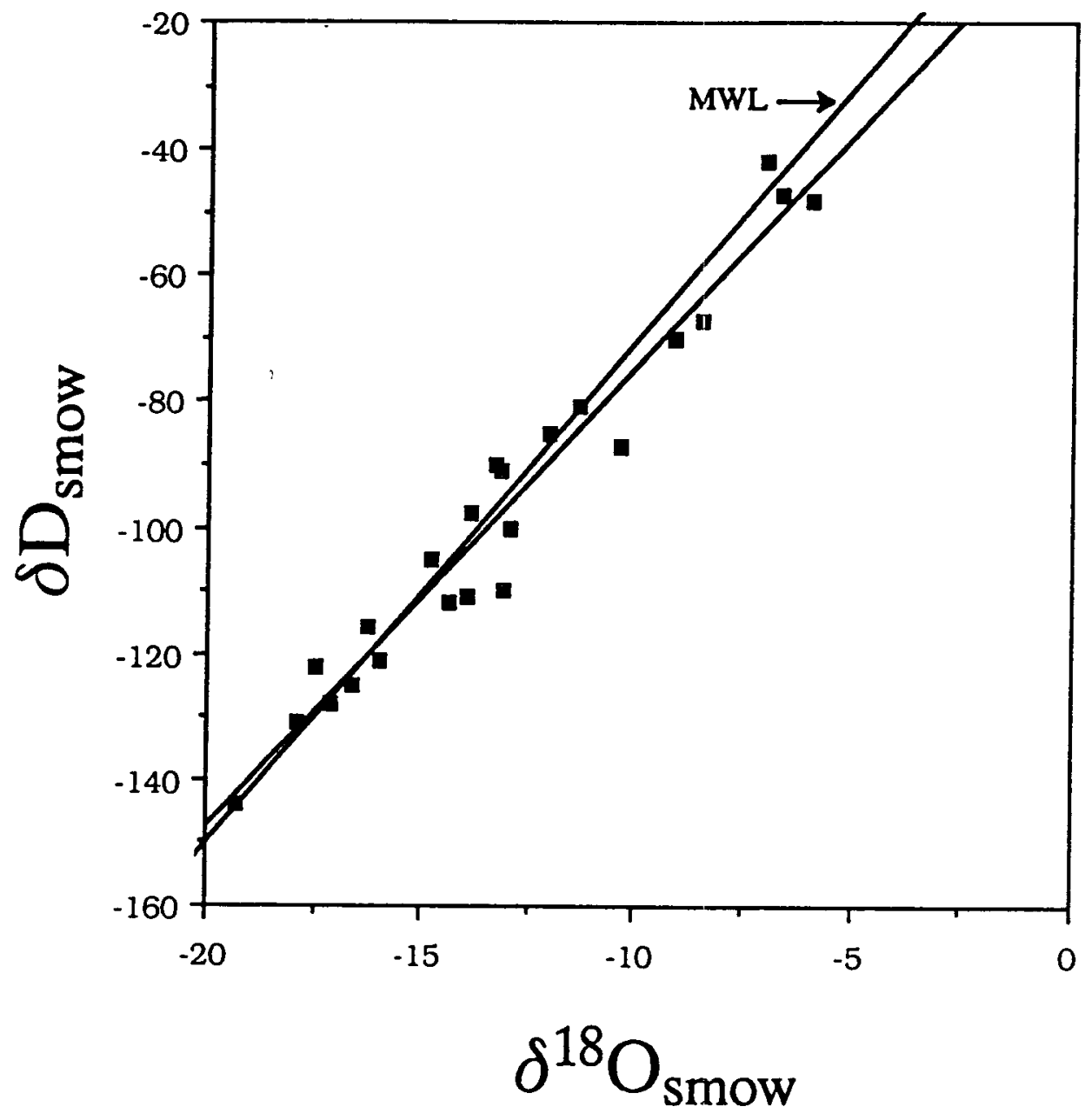

FIGURE 7. Available Pairs of the Stable Isotopic Composition of Precipitation for Collection Site RT2 Regardless of Amount. Also shown are the Best Fit Regression Line and the Meteoric Water Line. 


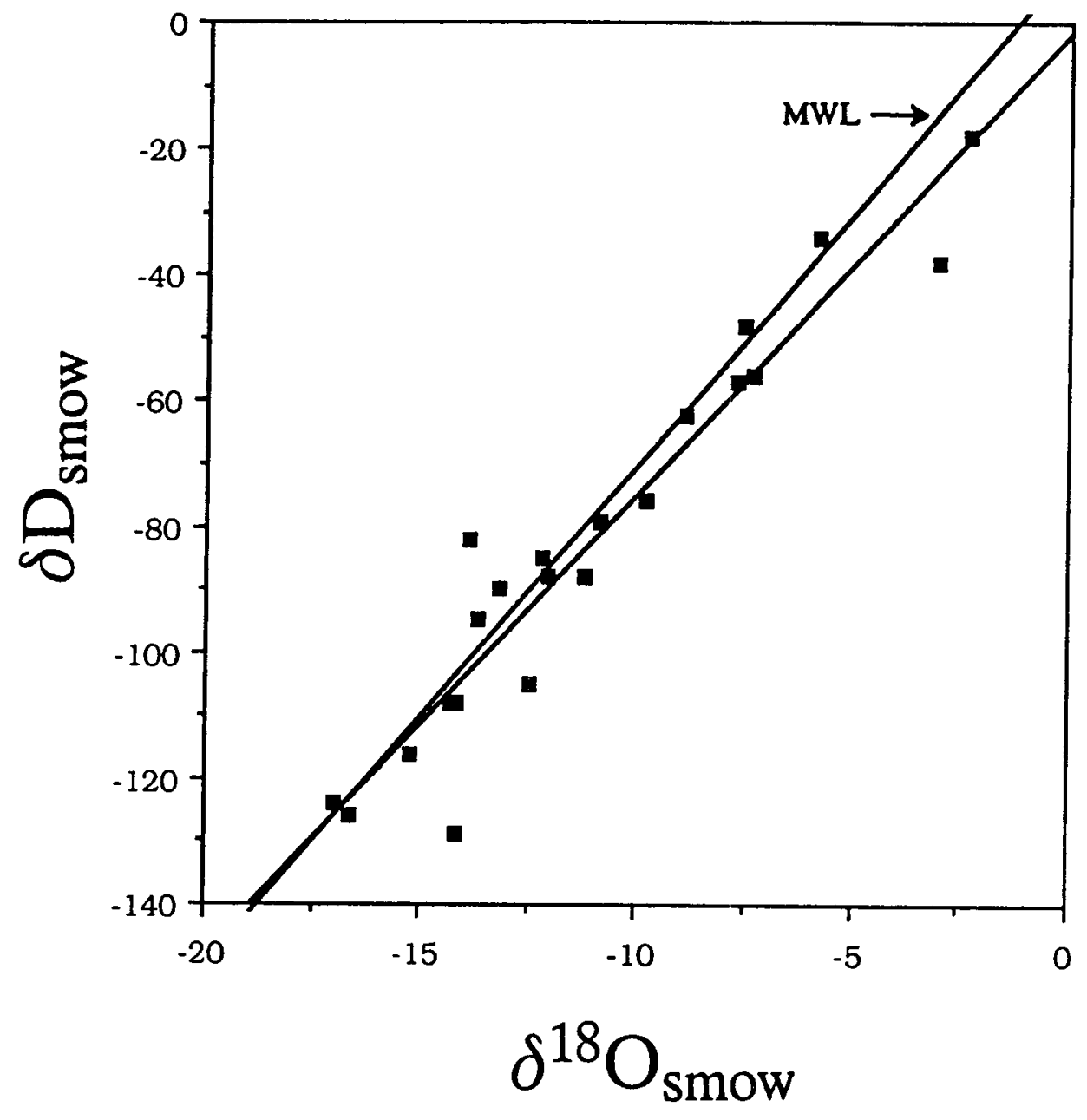

FIGURE 8. Available Pairs of the Stable Isotopic Composition of Precipitation for Collection Site RT3 Regardless of Amount. Also shown are the Best Fit Regression Line and the Meteoric Water Line. 


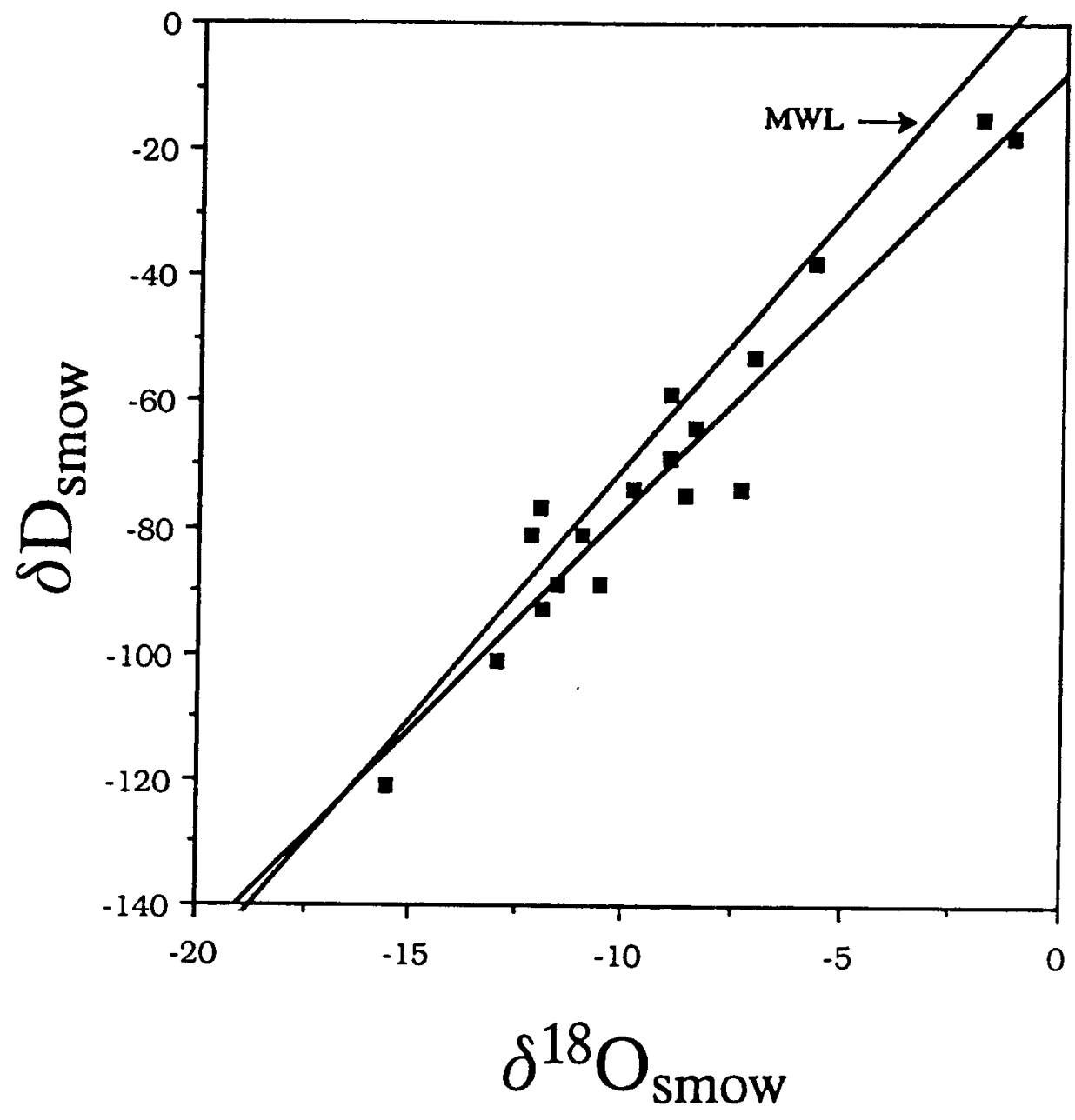

FIGURE 9. Available Pairs of the Stable Isotopic Composition of Precipitation for Collection Site SB1 Regardless of Amount. Also shown are the Best Fit Regression Line and the Meteoric Water Line. 


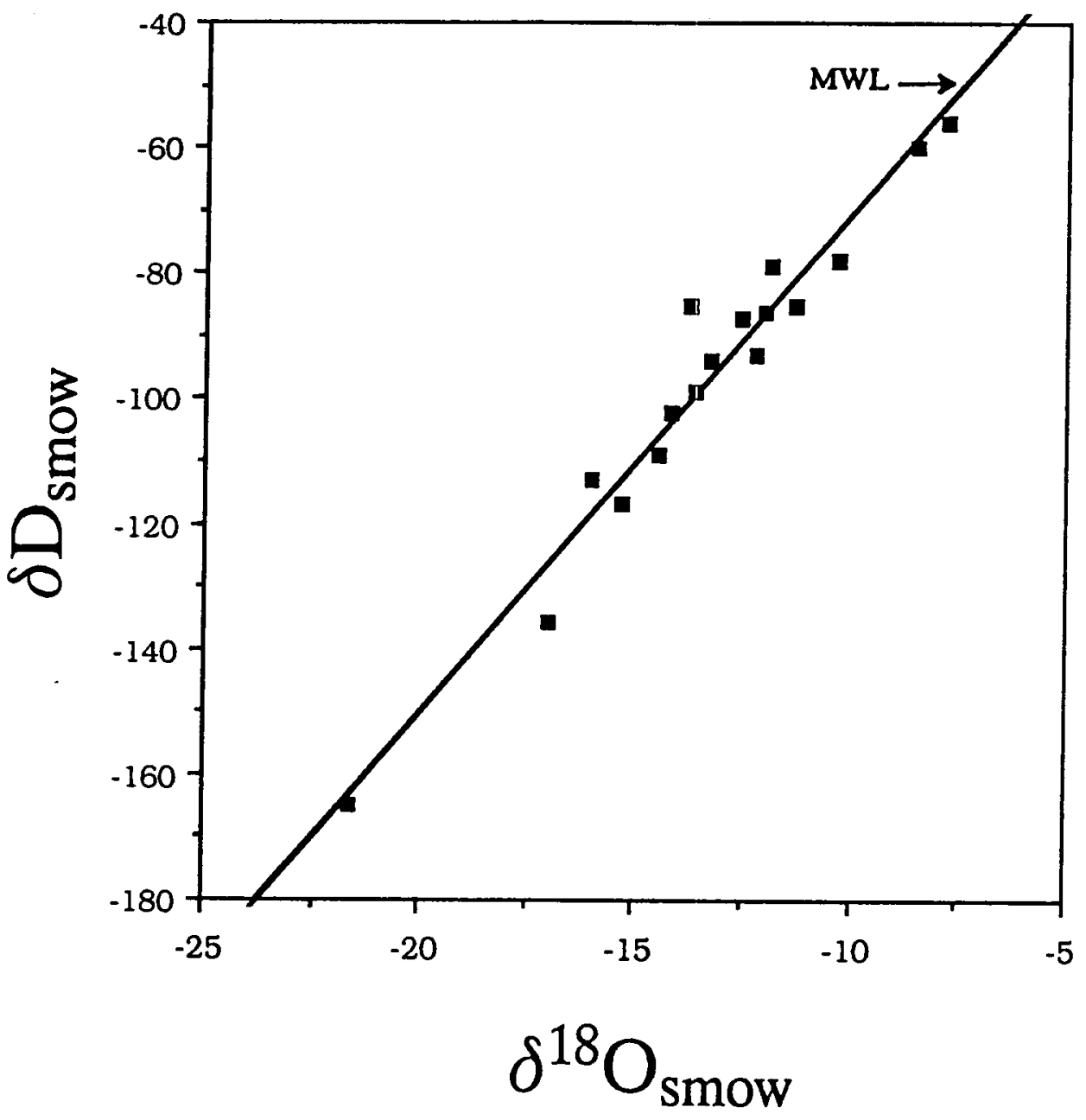

FIGURE 10. Available Pairs of the Stable Isotopic Composition of Precipitation for Collection Site ST1 Regardless of Amount. Also shown are the Best Fit Regression Line and the Meteoric Water Line. 


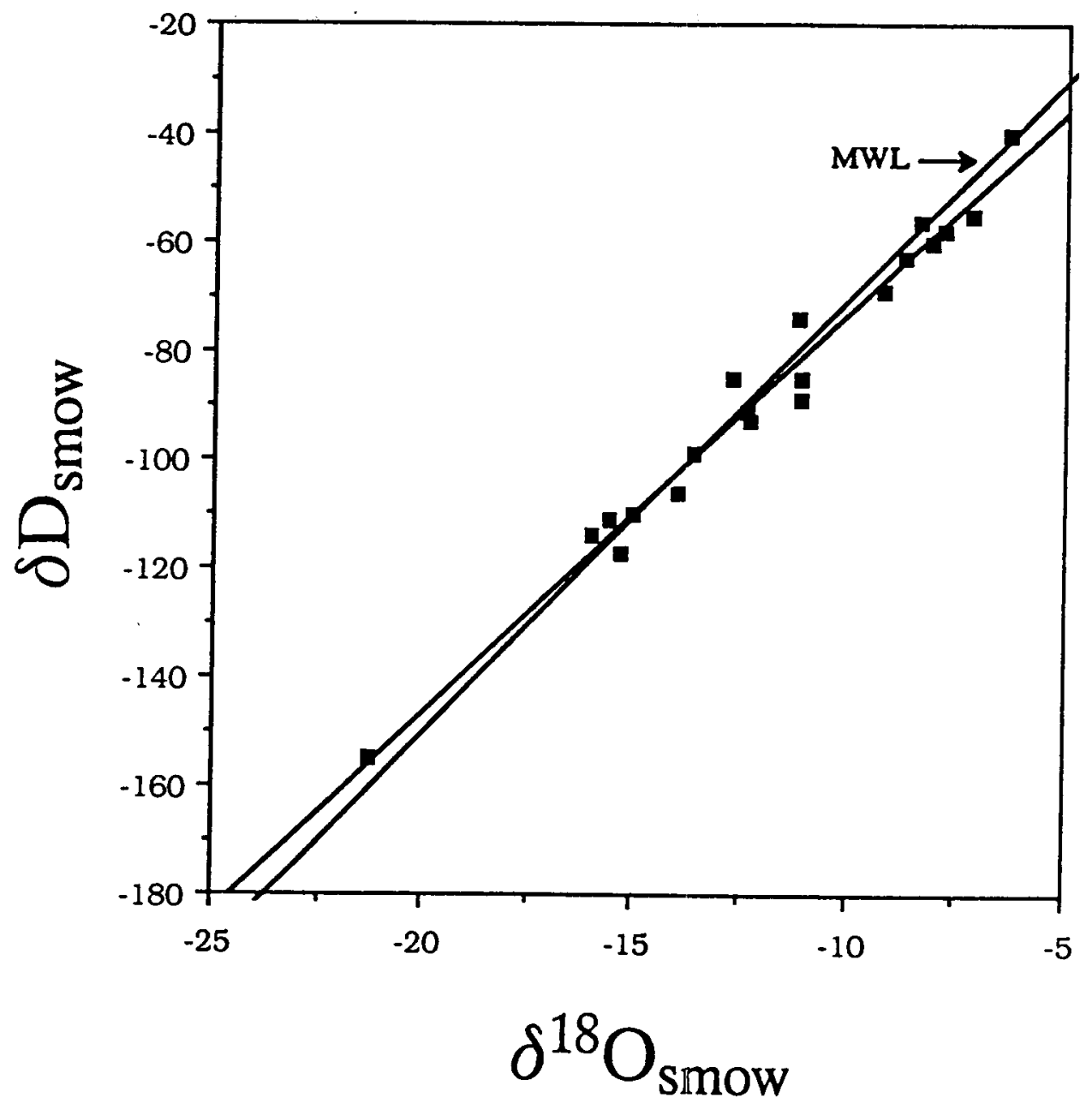

FIGURE 11. Available Pairs of the Stable Isotopic Composition of Precipitation for Collection Site ST2 Regardless of Amount. Also shown are the Best Fit Regression Line and the Meteoric Water Line. 


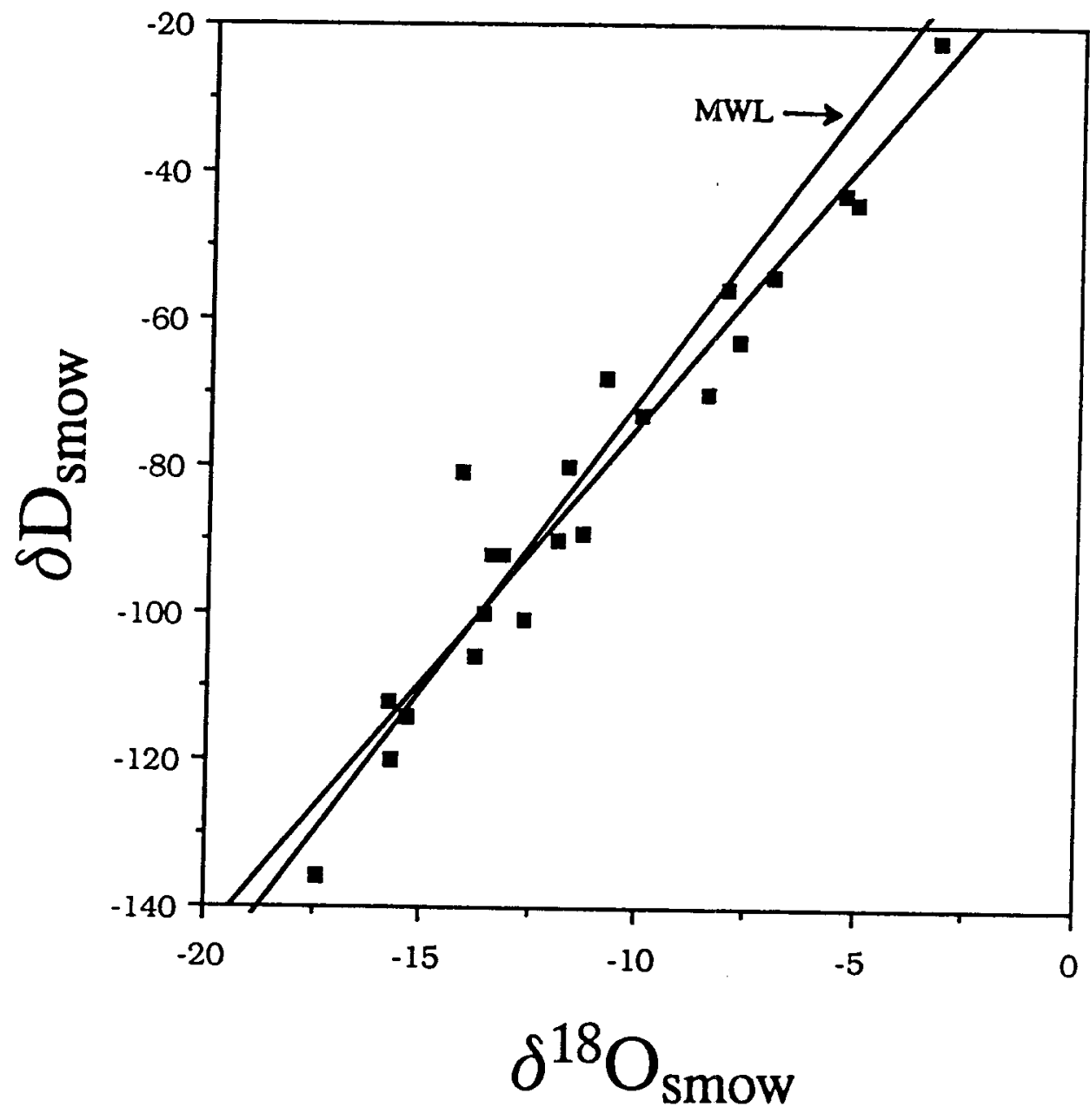

FIGURE 12. Available Pairs of the Stable Isotopic Composition of Precipitation for Collection Site ST3 Regardless of Amount. Also shown are the Best Fit Regression Line and the Meteoric Water Line. 


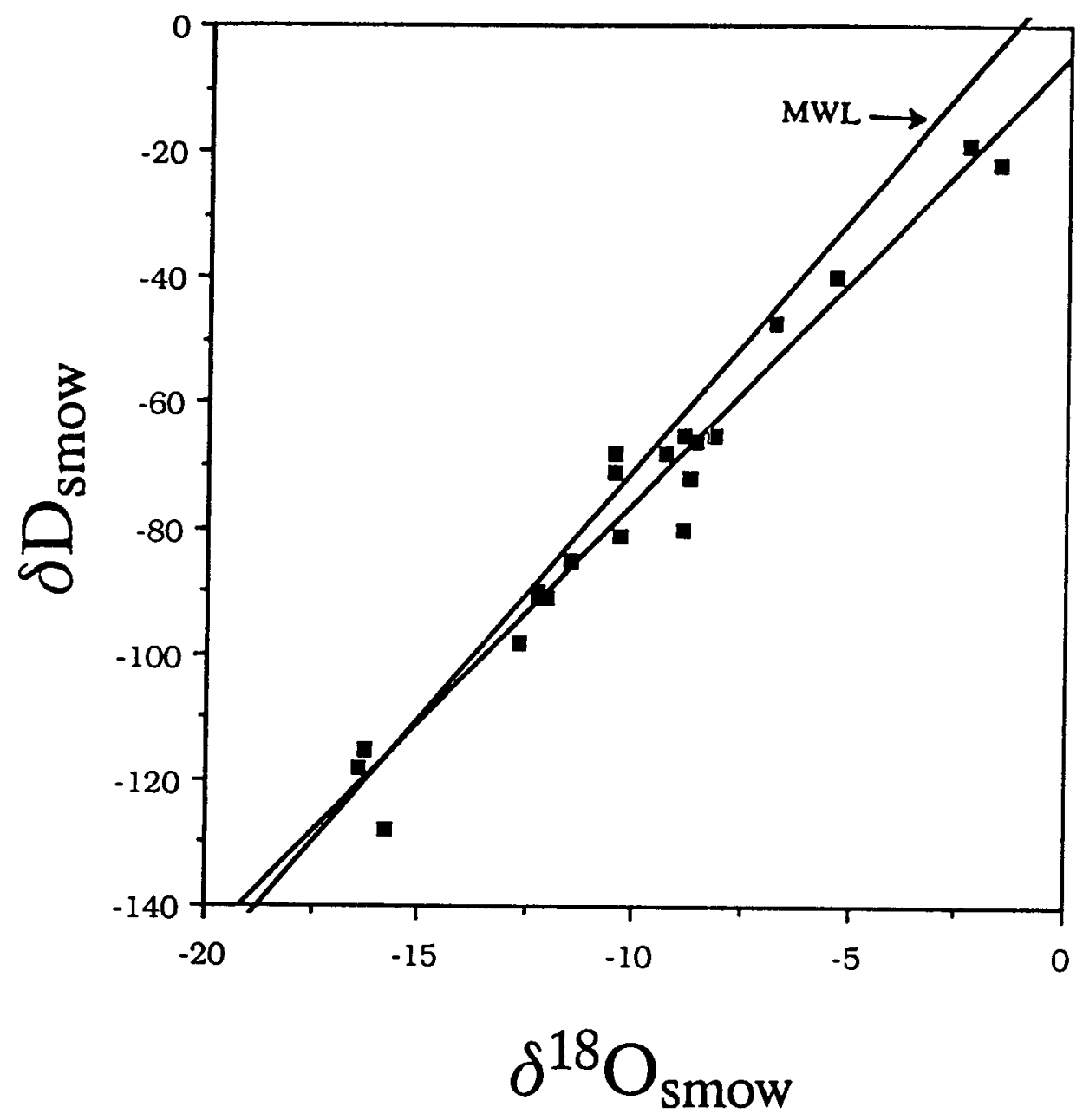

FIGURE 13. Available Pairs of the Stable Isotopic Composition of Precipitation for Collection Site ST4 Regardless of Amount. Also shown are the Best Fit Regression Line and the Meteoric Water Line. 


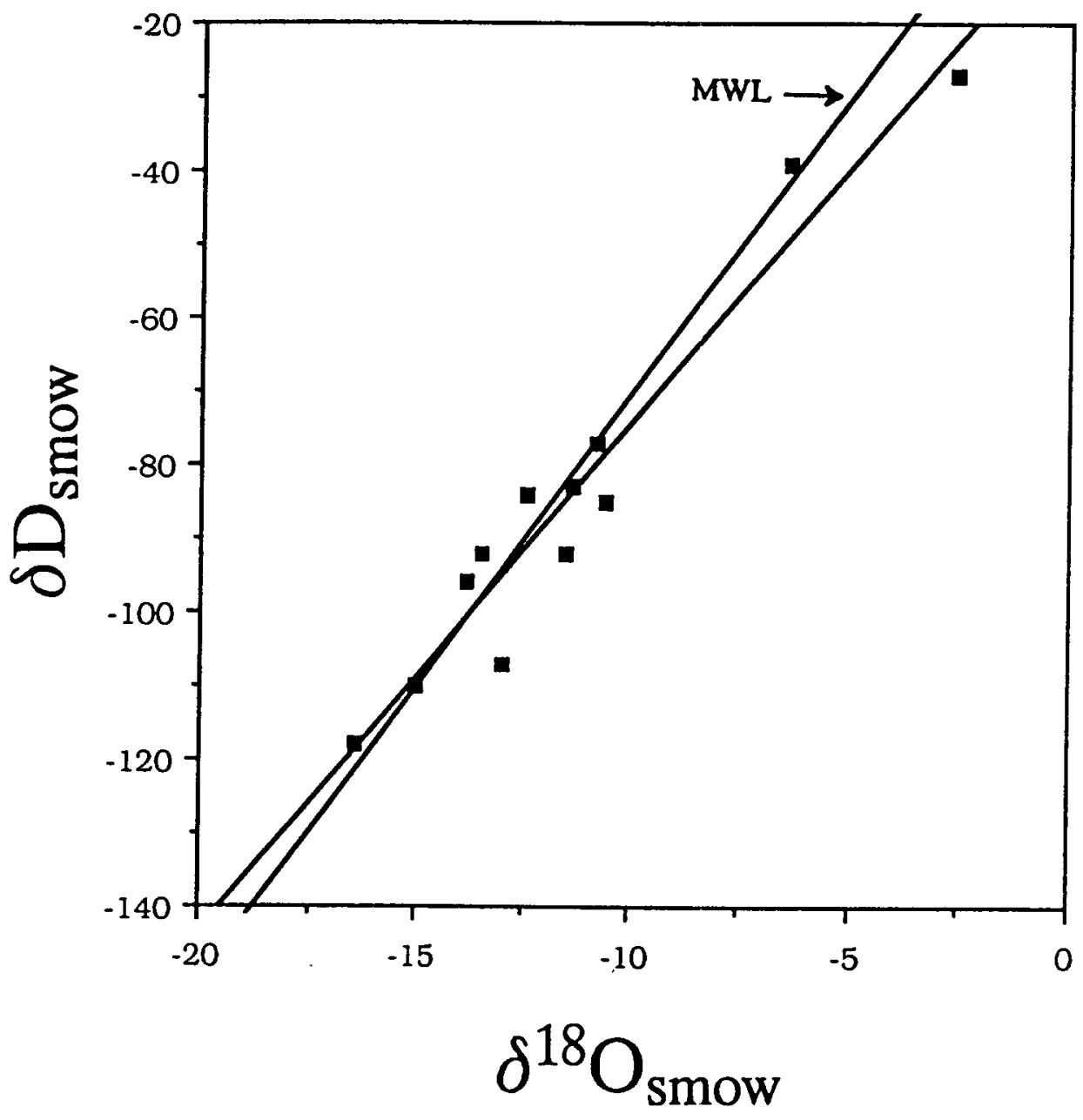

FIGURE 14. Available Pairs of the Stable Isotopic Composition of Precipitation for Collection Site TT1 Regardless of Amount. Also shown are the Best Fit Regression Line and the Meteoric Water Line. 


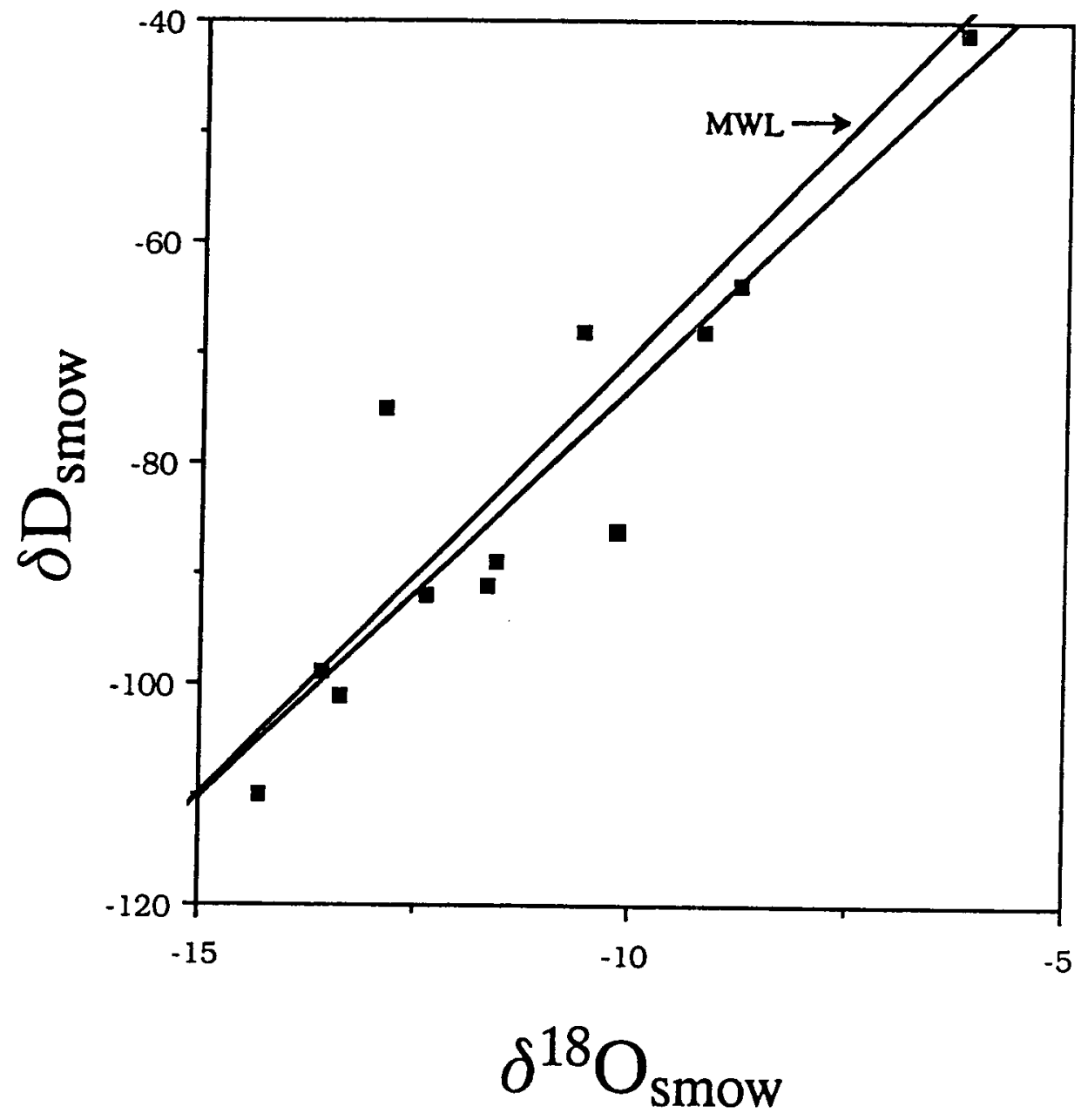

FIGURE 15. Available Pairs of the Stable Isotopic Composition of Precipitation for Collection Site TT2 Regardless of Amount. Also shown are the Best Fit Regression Line and the Meteoric Water Line. 


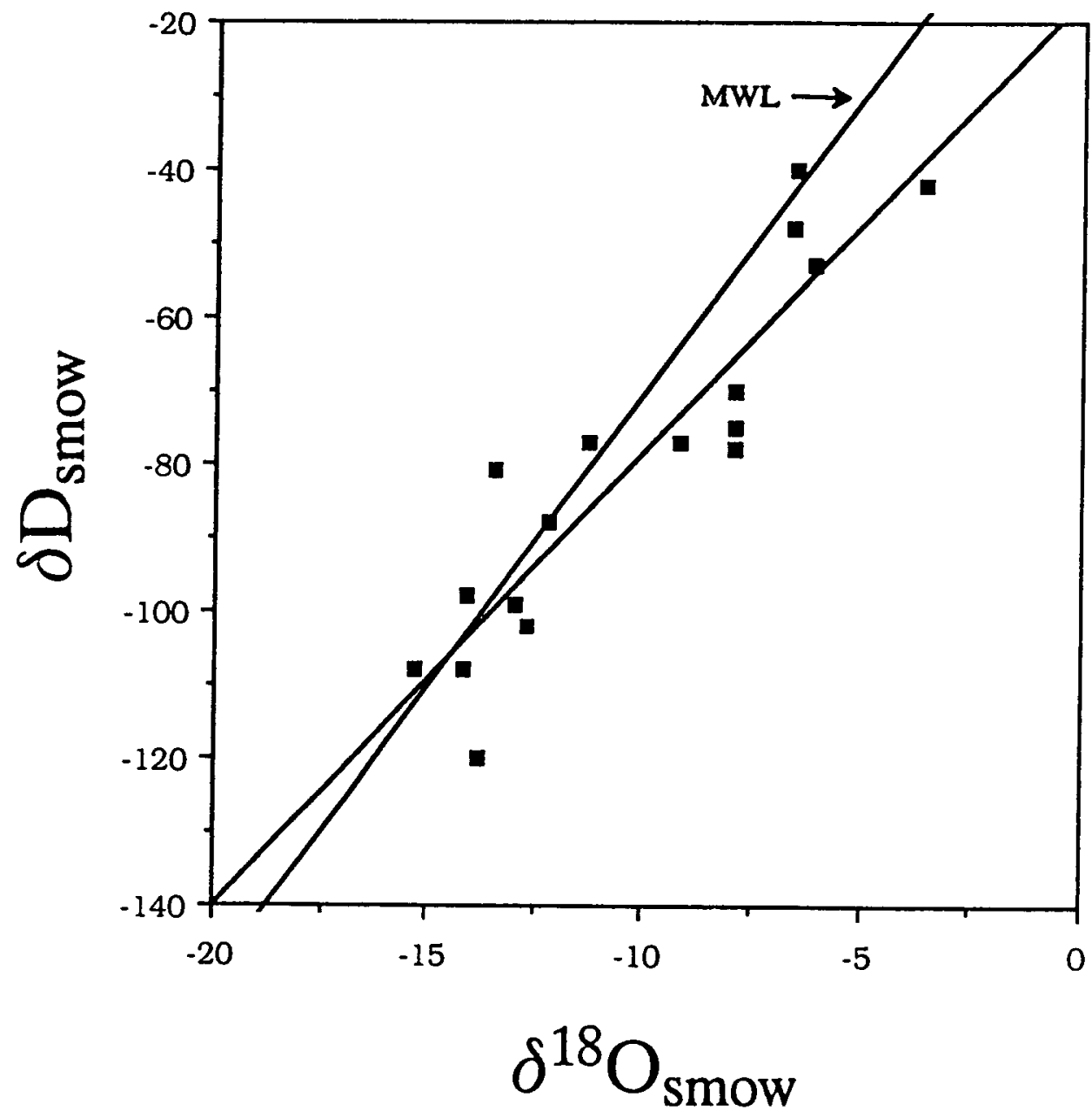

FIGURE 16. Available Pairs of the Stable Isotopic Composition of Precipitation for Collection Site TT3 Regardless of Amount. Also shown are the Best Fit Regression Line and the Meteoric Water Line. 


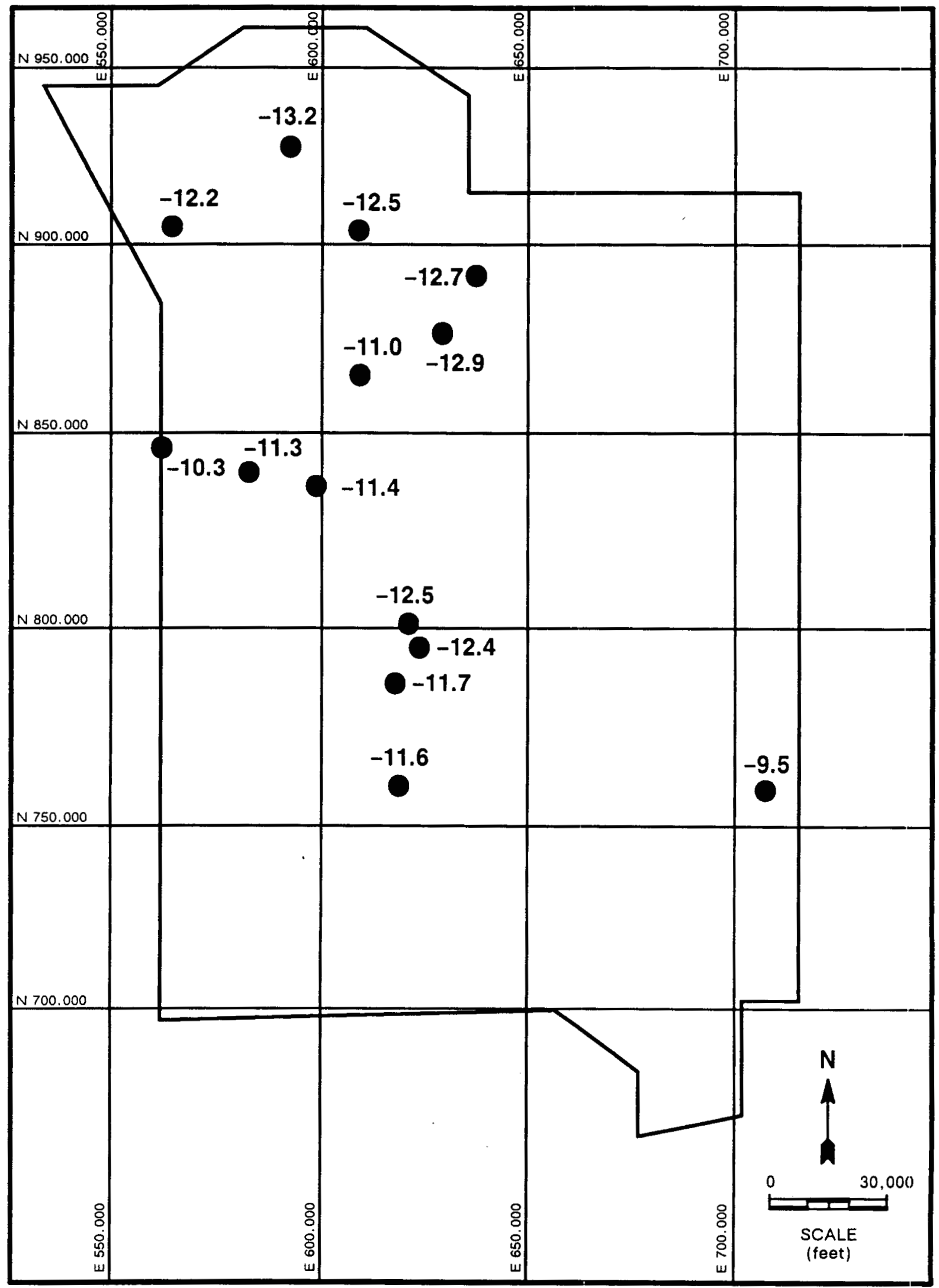

FIGURE 17. Location Map Showing the Weighted Average in $\delta^{18} \mathrm{O}$ of Precipitation at each Collection Site. 


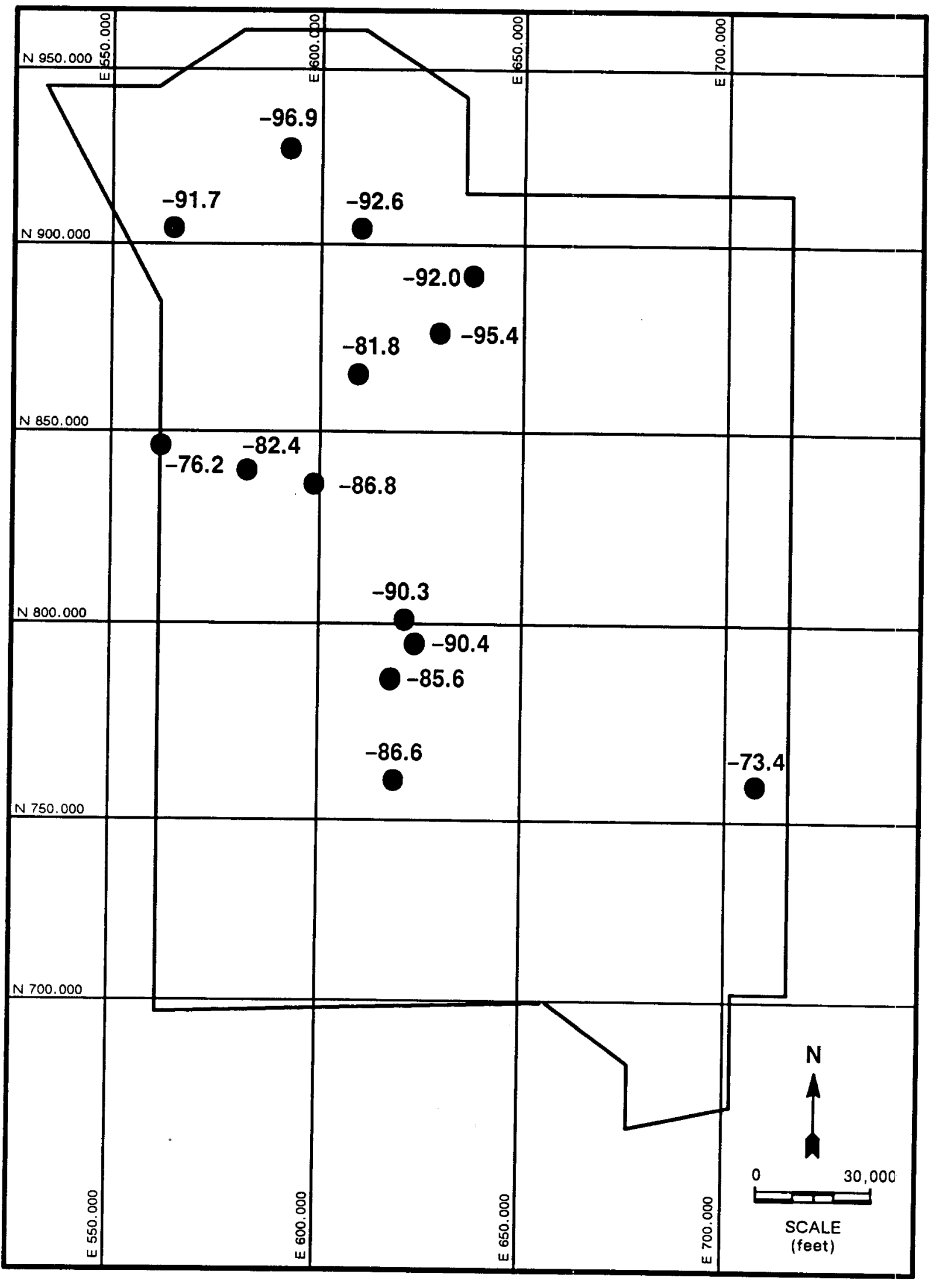

FIGURE 18. Location Map Showing the Weighted Average in $\delta D$ of Precipitation at each Collection Site. 
TABLE 2. THE WEIGHTED AVERAGES OF $\delta^{18} \mathrm{O}$ AND $\delta \mathrm{D}$ IN PRECIPITATION AND ELEVATION IN METERS (FEET) FOR EACH SAMPLING LOCATION.

\begin{tabular}{|c|c|c|c|c|}
\hline \multirow[b]{2}{*}{ Station } & \multirow[b]{2}{*}{$\delta^{18} \mathrm{O}^{\circ} \%$} & \multirow[b]{2}{*}{$8 D \%$} & \multicolumn{2}{|c|}{ Elevation } \\
\hline & & & meters & (feet) \\
\hline SB1 & -9.5 & -73.4 & 960 & $(3160)$ \\
\hline ST4 & -11.6 & -86.6 & 1225 & (4020) \\
\hline TT3 & -11.4 & -86.8 & 1400 & (4600) \\
\hline ST3 & -11.7 & -85.6 & 1525 & $(5000)$ \\
\hline RT3 & -11.0 & -81.8 & 1590 & (5220) \\
\hline TT2 & -11.3 & -82.4 & 1630 & (5340) \\
\hline ST2 & -12.4 & -90.4 & 1830 & $(6000)$ \\
\hline TT1 & -10.3 & -76.2 & 1840 & (6040) \\
\hline PT3 & -12.2 & -91.7 & 1890 & (6200) \\
\hline RT2 & -12.9 & -95.4 & 1900 & $(6230)$ \\
\hline PT2 & -13.2 & -96.9 & 2060 & (6760) \\
\hline ST1 & -12.5 & -90.3 & 2135 & (7000) \\
\hline PT1 & -12.5 & -92.6 & 2200 & (7200) \\
\hline RT1 & -12.7 & -92.0 & 2235 & (7330) \\
\hline
\end{tabular}

tain. After July, the $\delta^{18} \mathrm{O}$ of precipitation decreases sharply until it averages about -14 per mil in December.

The total amounts of precipitation collected within each 0.5 per mil interval are compared in Figure 36. The weighted mean of the oxygen isotope compositions of all precipitation samples collected is -11.9 per mil, while the mode is between -13.0 and -14.5 per mil. This plot also shows a rather flat plateau between -4 and -12 per mil for the summer rain (June through October), and a very sharp peak between -12.5 and -14.5 per mil for the winter rain (November through May).

\section{Spring Discharge}

The discharges (in liters/min) from Whiterock Spring and Cane Spring are plotted in Figures 37 and 38, respectively, along with the precipitation amounts collected nearby. Whiterock Spring displays considerable variation in discharge, which was first noted by Thordarson (1965), who related increases in discharge from Whiterock Spring to large precipitation events. Whiterock Spring shows a much more direct response to the peaks in precipitation than Cane Spring. This is especially evident for the five peaks in the discharge of Whiterock Spring through early 1986 . However, after early 1985, Whiterock Spring discharge appears to moderate, apparently in response to the moderation of pre- 


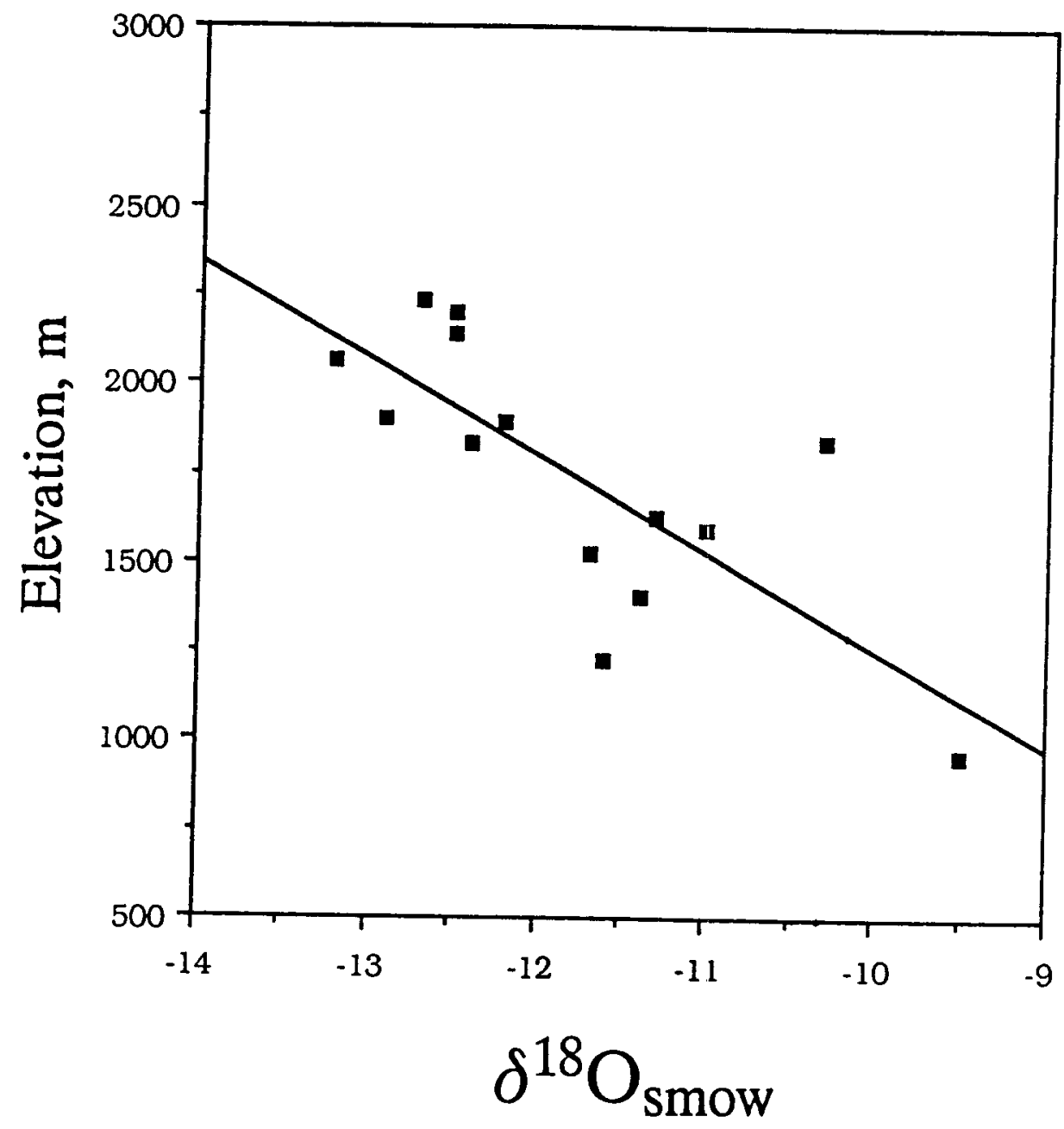

FIGURE 19. Weighted Average of the Oxygen Isotopic Ratios vs. Elevation for each Collection Site. 
TABLE 3. THE WEIGHTED AVERAGES OF $\delta^{18} \mathrm{O}$ IN PRECIPITATION BY YEAR OF COLLECTION.

\begin{tabular}{cc}
\hline Year & Weighted Average, $\delta^{18} \mathrm{O}$ \\
\hline 1982 & -10.3 \\
1983 & -11.2 \\
1984 & -10.4 \\
1985 & -10.0 \\
1986 & -12.3 \\
\hline
\end{tabular}

cipitation commencing in late 1983. Similar correlations between precipitation peaks and discharge peaks are observed for Cane Spring, however, they are not as obvious. As with the precipitation records for Whiterock Spring, the variation in precipitation near Cane Spring also moderates commencing in late 1983.

Cane and Whiterock Springs were monitored for their stable isotopic composition as well as discharge. In addition, several samples from each spring were collected and analyzed for tritium, which was detected in the discharge water of Whiterock Spring (45 and $80 \mathrm{pCi} / 1 ; 1-10-85$ and 3-26-82, respectively), but not in Cane Spring ( $<16 \mathrm{pCi} / \mathrm{l}$; $3-26-82,6-6-84,11-15-84,1-10-85)$. This prompted a ${ }^{14} \mathrm{C}$ analysis of Cane Spring (3-14-82), which resulted in an uncorrected age of about 600 years for the water.

The available stable isotopic pairs $\left(\delta \mathrm{D}\right.$ and $\left.\delta^{18} \mathrm{O}\right)$ of discharge water from Whiterock Spring and Cane Spring are shown in Figure 39, along with the meteoric water line (Craig, 1961 ) and the local meteoric water line (LMWL: $\delta D=6.87 \delta^{18} \mathrm{O}-6.5$ ) of this research. The waters plot in two separate fields, waters from Cane Spring are generally a little more enriched in both deuterium and ${ }^{18} \mathrm{O}$ than those from Whiterock Spring. The enrichment observed in the water from both springs is probably due, in large part, to evaporation while the water is impounded in the adit. The larger shift in the waters from Cane Spring represents a longer residence time in the pool in the adit. Thus, the true stable isotopic composition of the discharge water of these springs is unknown. Nevertheless, large stable isotopic variations are observed in the discharge water and are thought to represent the stable isotopic fluctuation in precipitation.

The stable oxygen isotopic compositions of discharge water from Cane and Whiterock Springs, for the period of collection, are shown in Figure 40. Both springs show considerable fluctuation, but display the fluctuation in unison. However, Whiterock Spring appears to fluctuate to a much greater degree than Cane Spring. 


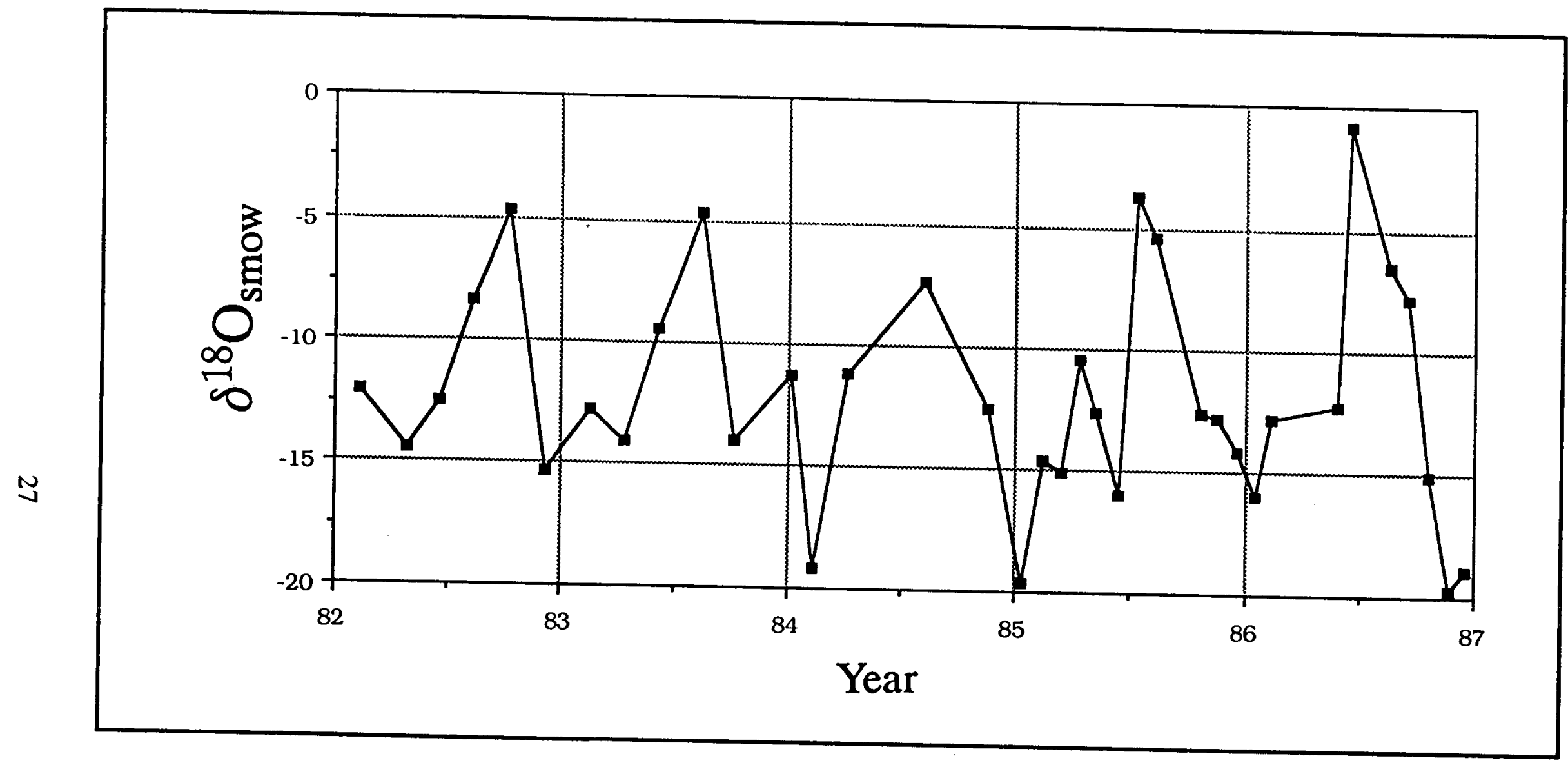

FIGURE 20. Time Series of the Weighted Average of the Oxygen Isotope Composition of Precipitation from Site PT1 During the Period of Collection. 


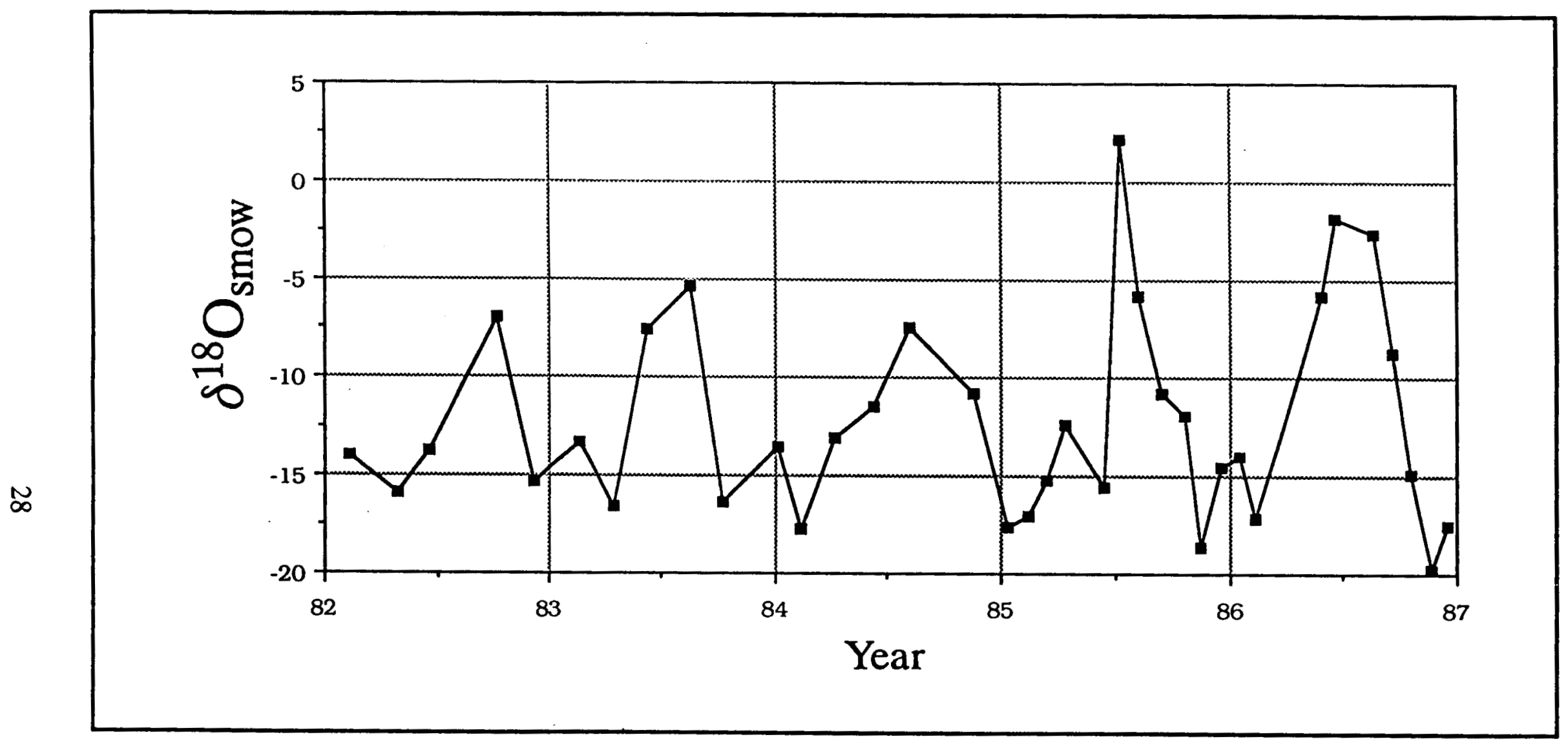

FIGURE 21. Time Series of the Weighted Average of the Oxygen Isotope Composition of Precipitation from Site PT2 During the Period of Collection. 


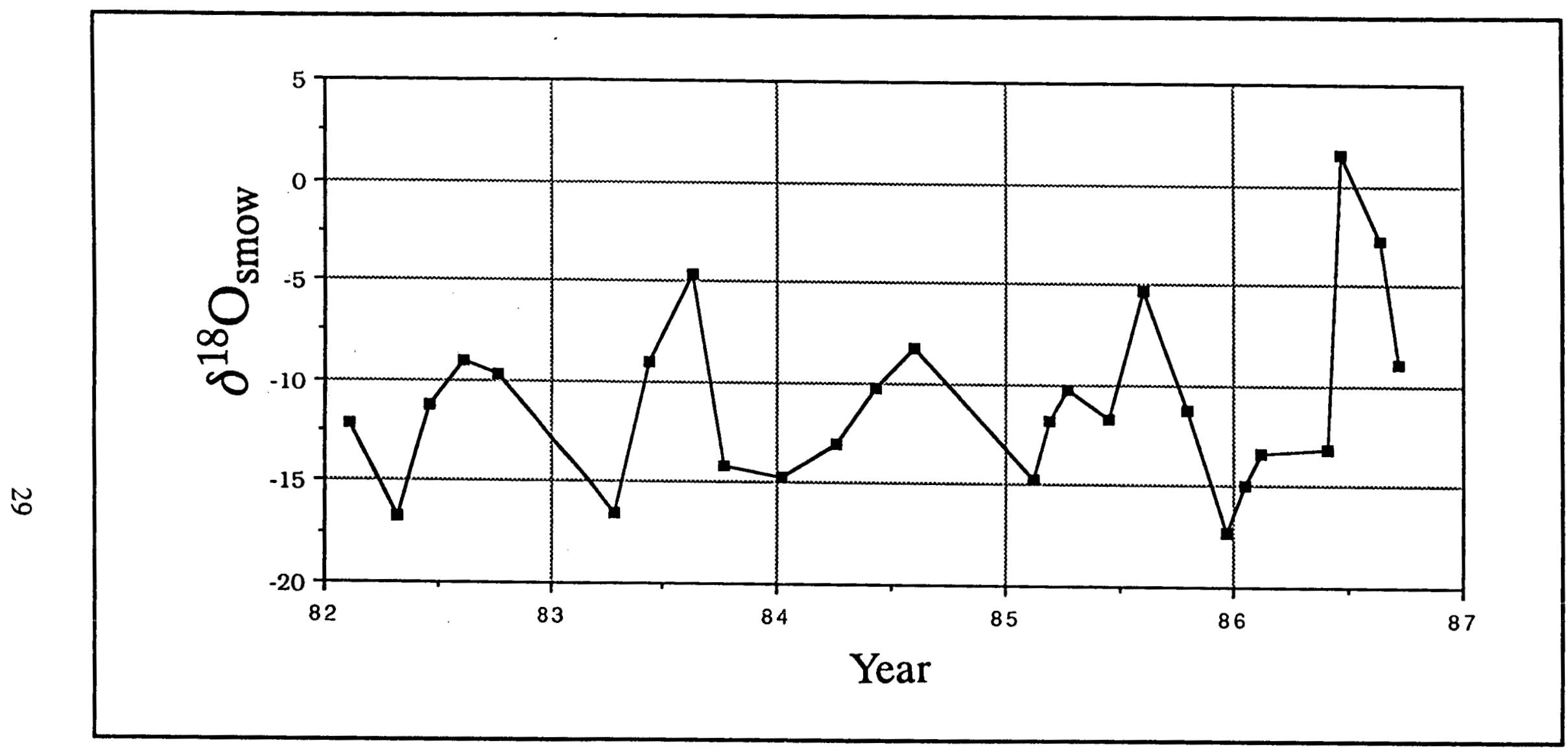

FIGURE 22. Time Series of the Weighted Average of the Oxygen Isotope Composition of Precipitation from Site PT3 During the Period of Collection. 


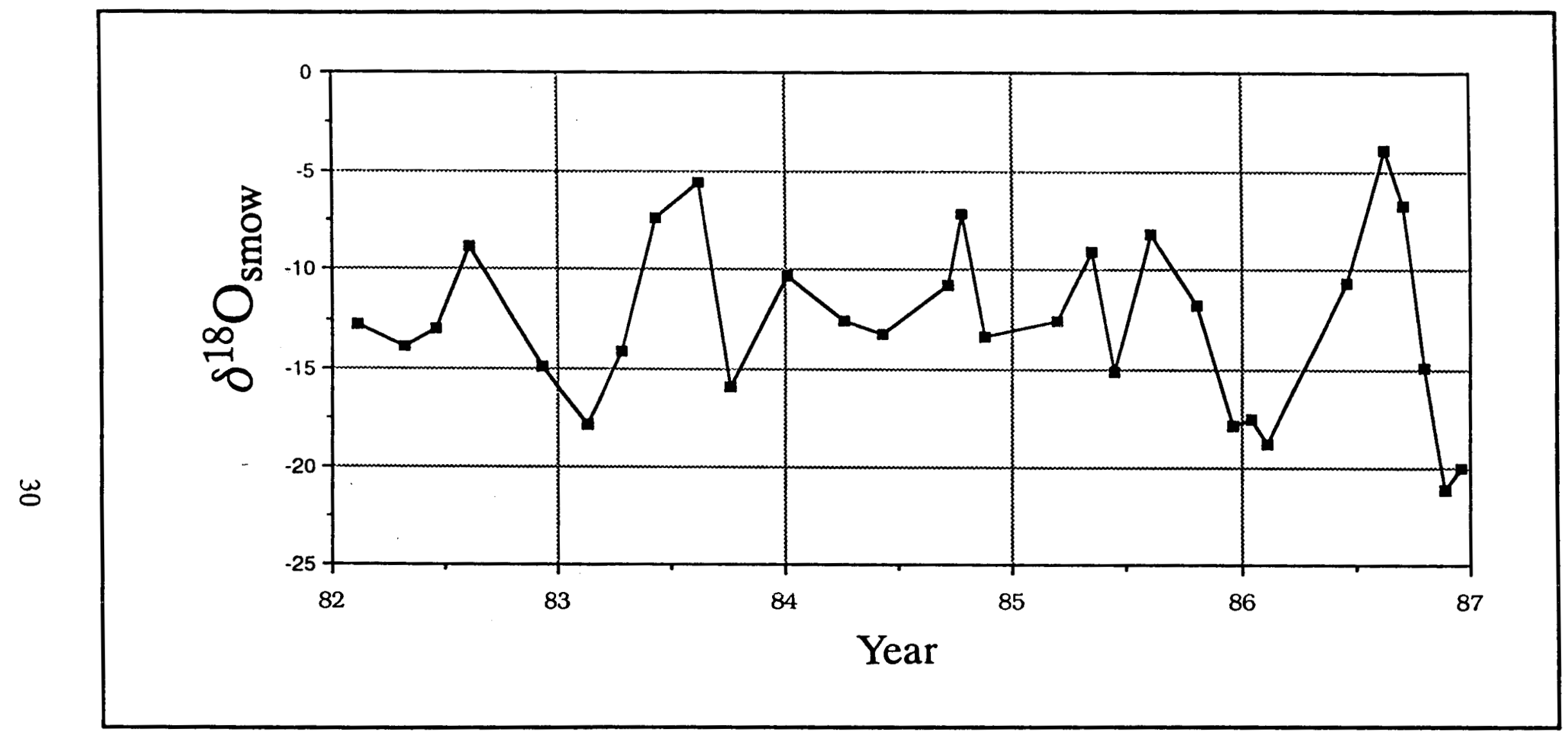

FIGURE 23. Time Series of the Weighted Average of the Oxygen Isotope Composition of Precipitation from Site RT1 During the Period of Collection. 


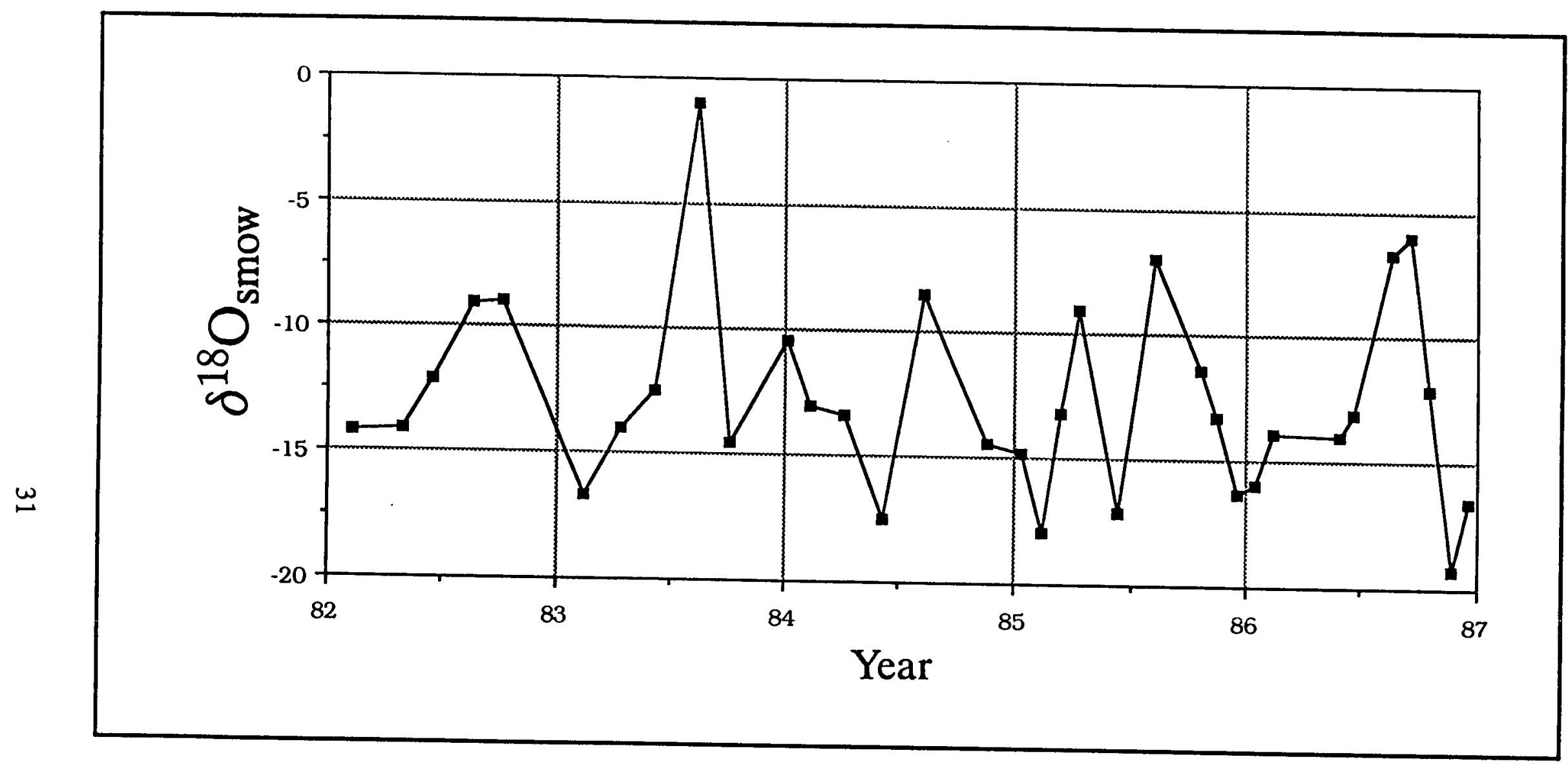

FIGURE 24. Time Series of the Weighted Average of the Oxygen Isotope Composition of Precipitation from Site RT2 During the Period of Collection. 


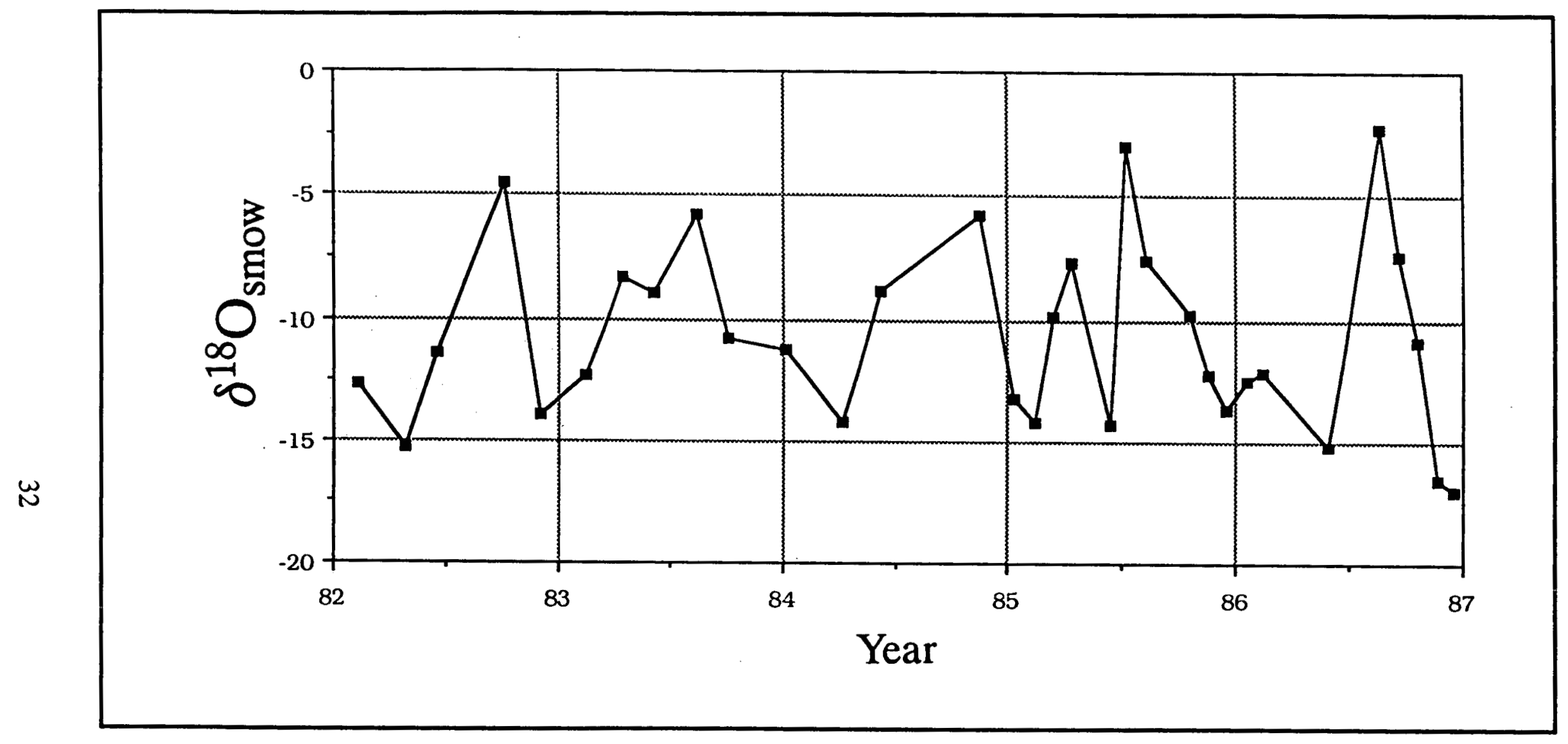

FIGURE 25. Time Series of the Weighted Average of the Oxygen Isotope Composition of Precipitation from Site RT3 During the Period of Collection. 


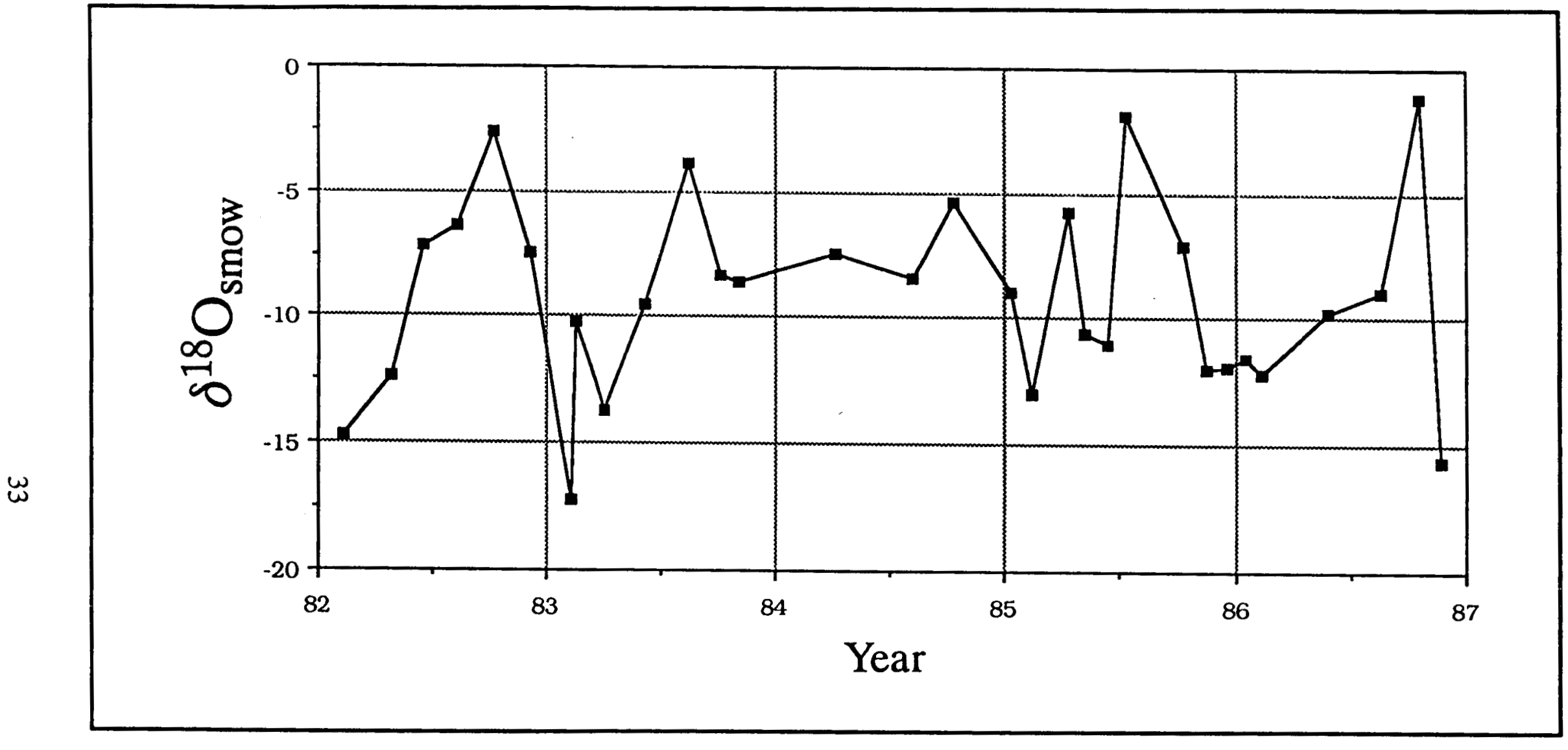

FIGURE 26. Time Series of the Weighted Average of the Oxygen Isotope Composition of Precipitation from Site SB1 During the Period of Collection. 


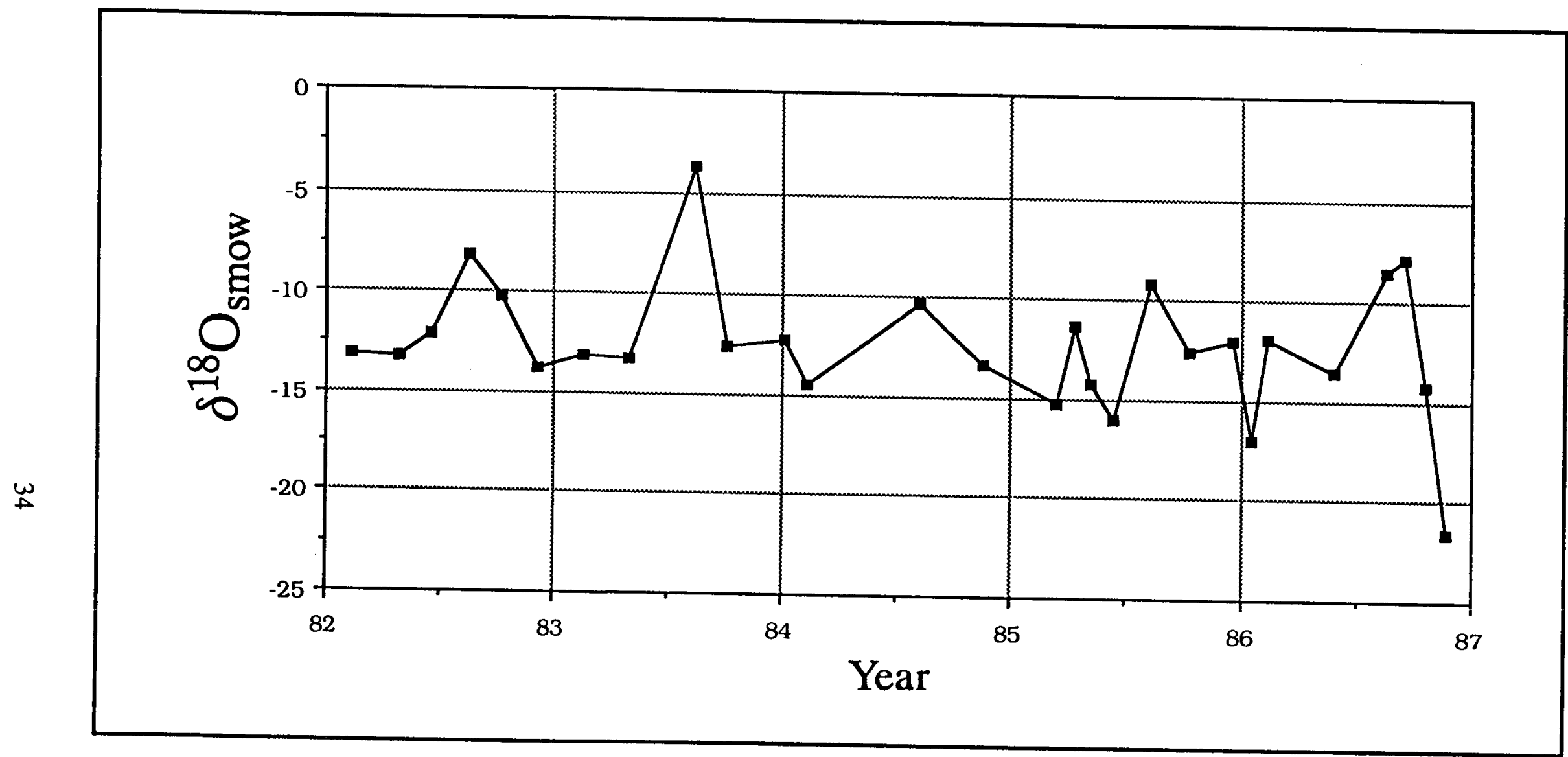

FIGURE 27. Time Series of the Weighted Average of the Oxygen Isotope Composition of Precipitation from Site ST1 During the Period of Collection. 


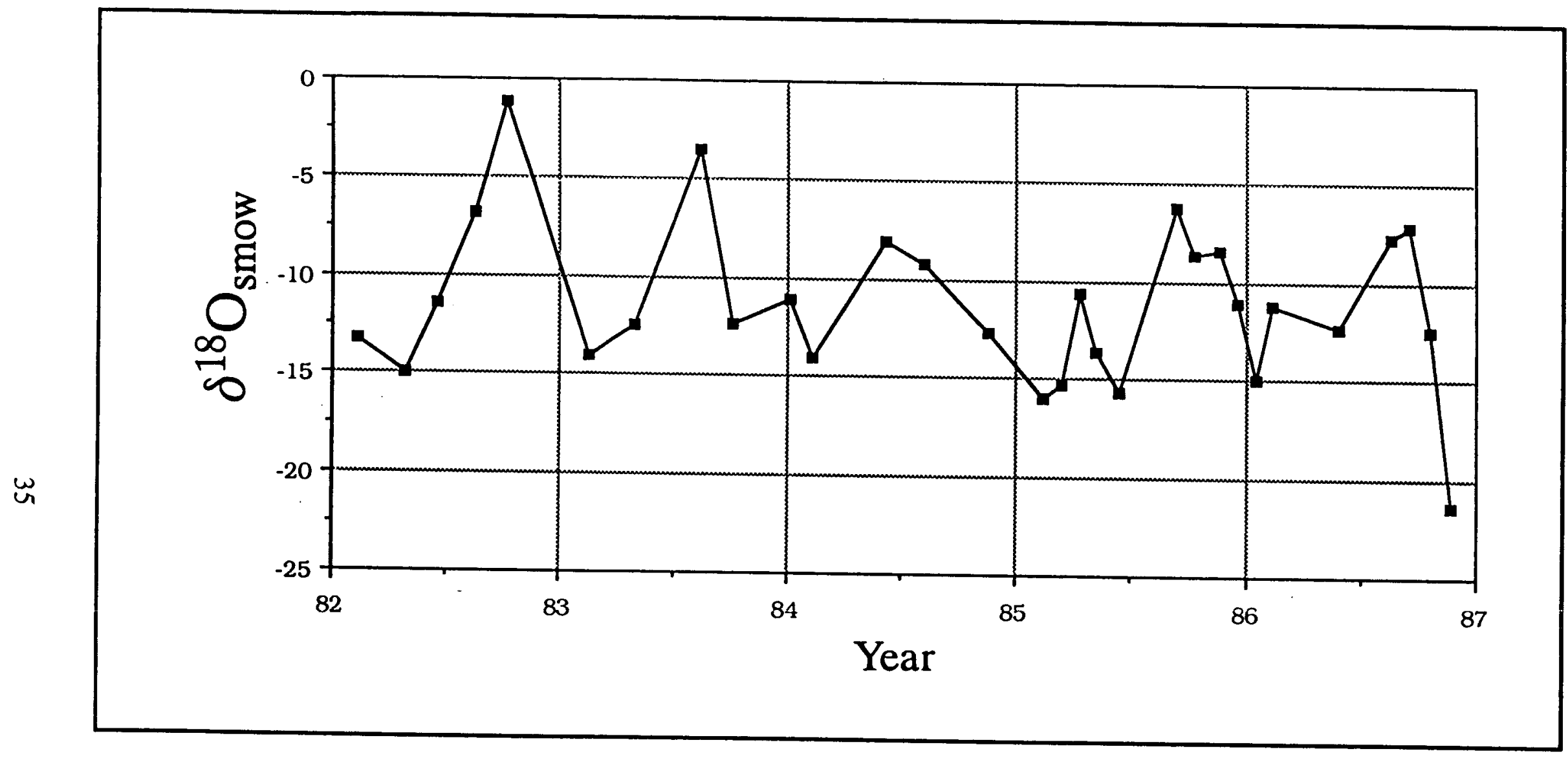

FIGURE 28. Time Series of the Weighted Average of the Oxygen Isotope Composition of Precipitation from Site ST2 During the Period of Collection. 


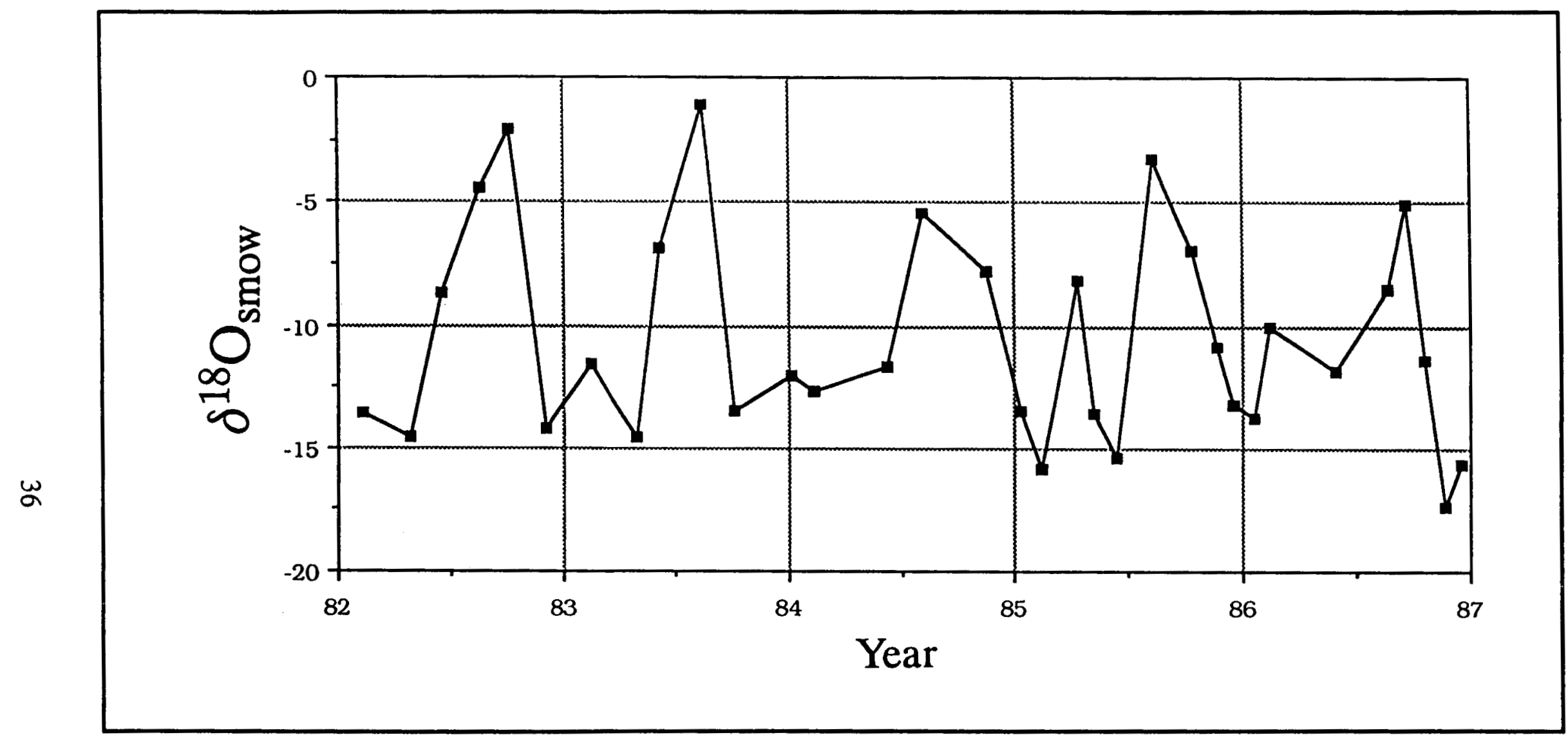

FIGURE 29. Time Series of the Weighted Average of the Oxygen Isotope Composition of Precipitation from Site ST3 During the Period of Collection. 


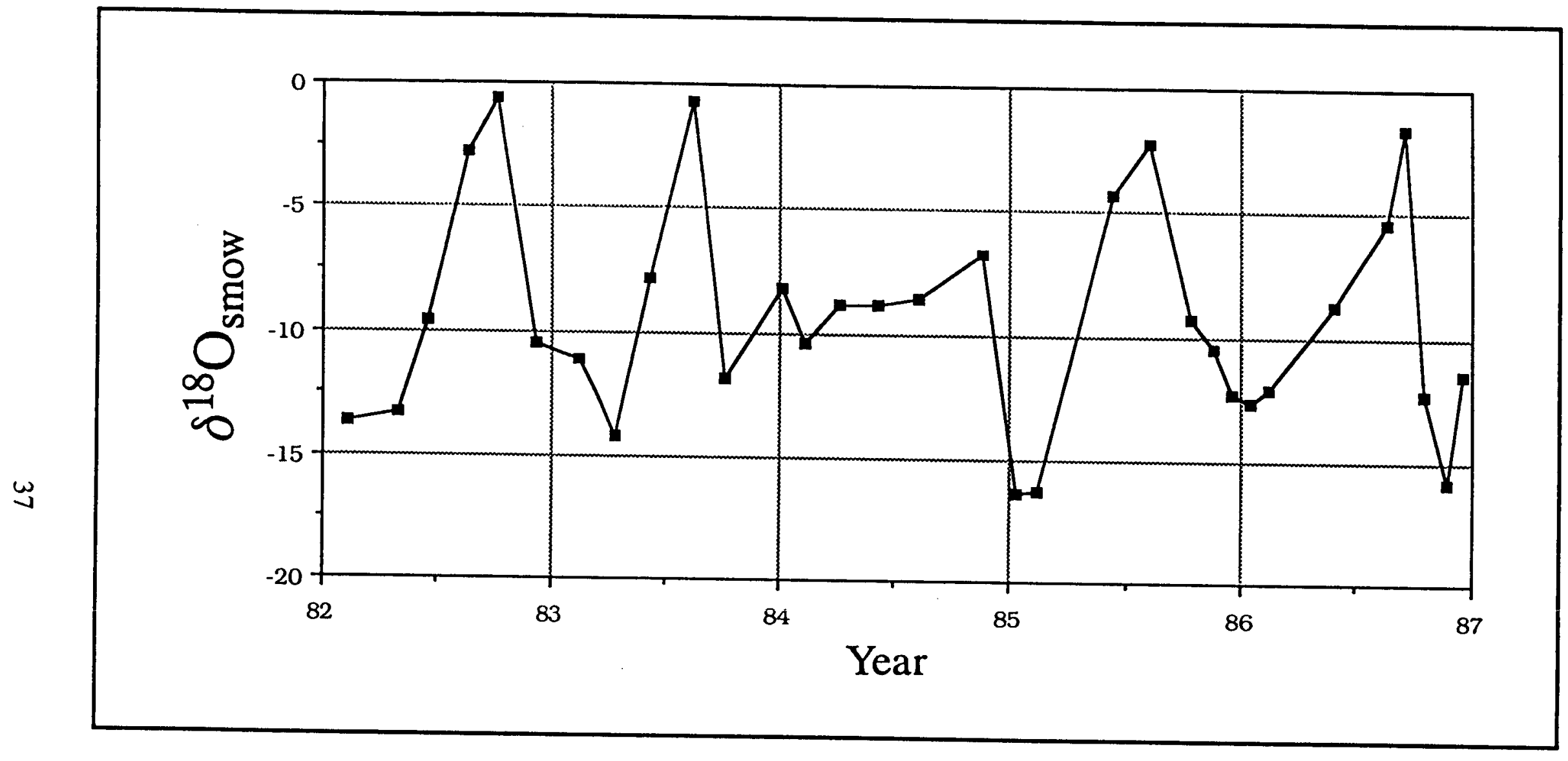

FIGURE 30. Time Series of the Weighted Average of the Oxygen Isotope Composition of Precipitation from Site ST4 During the Period of Collection. 


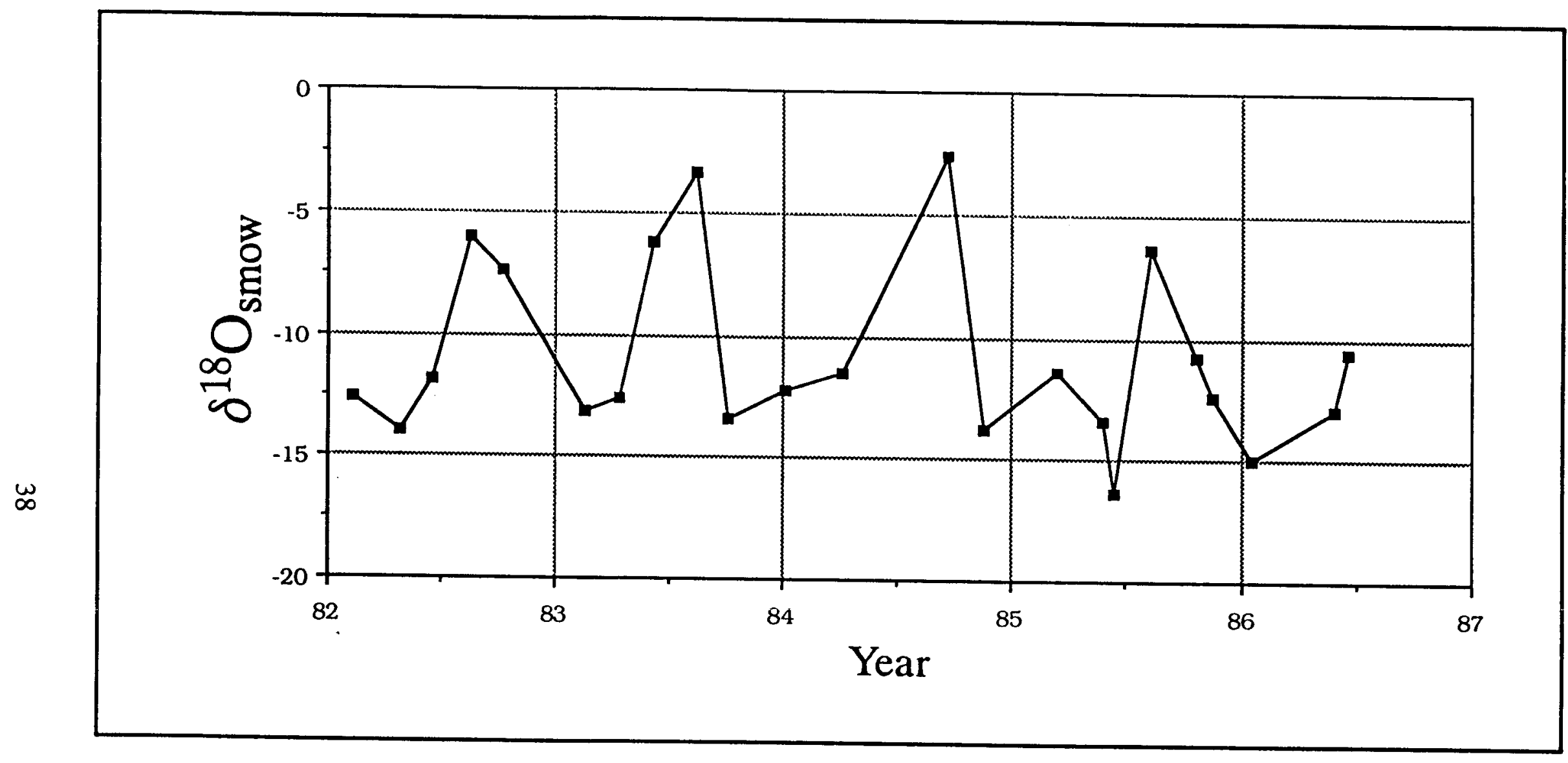

FIGURE 31. Time Series of the Weighted Average of the Oxygen Isotope Composition of Precipitation from Site TT1 During the Period of Collection. 


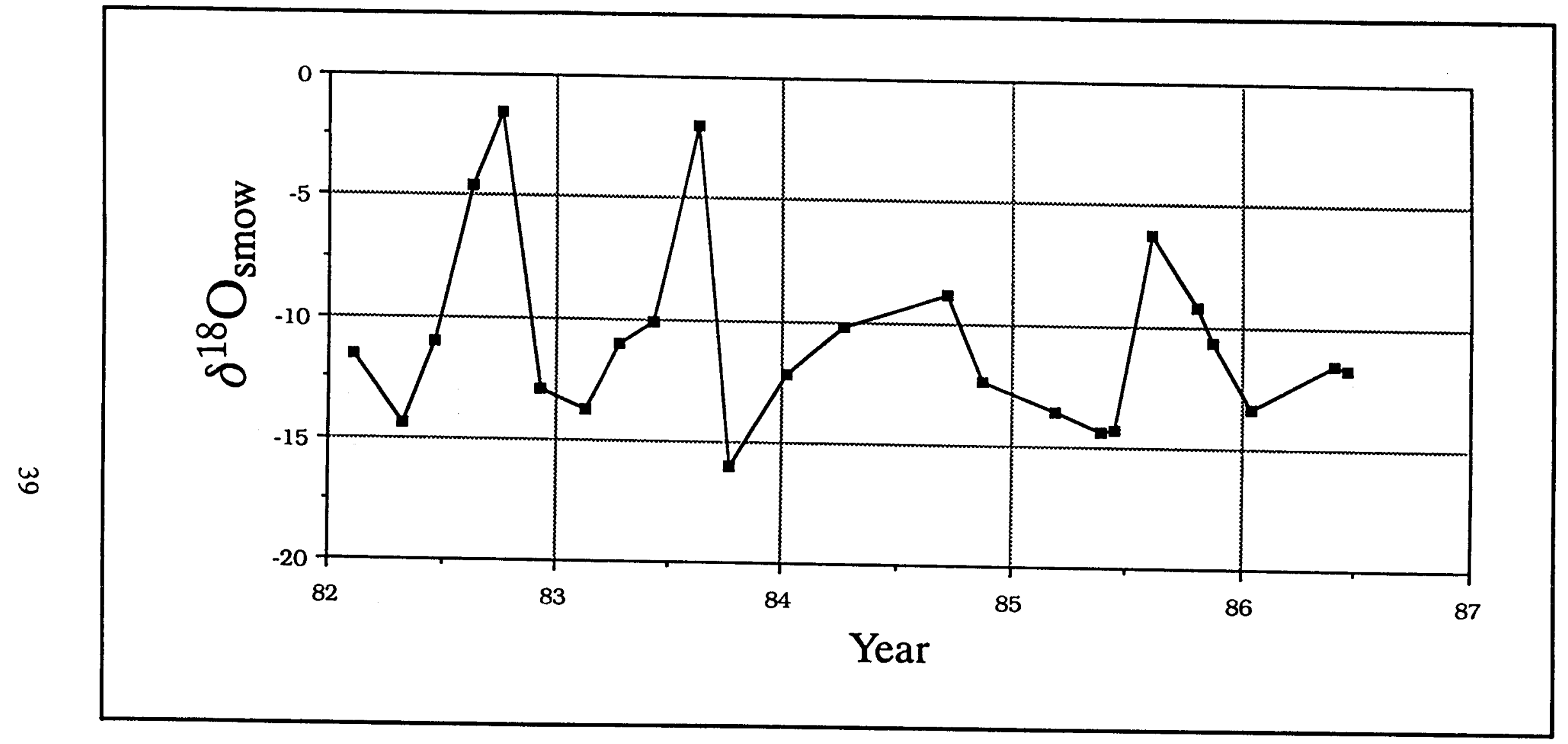

FIGURE 32. Time Series of the Weighted Average of the Oxygen Isotope Composition of Precipitation from Site TT2 During the Period of Collection. 


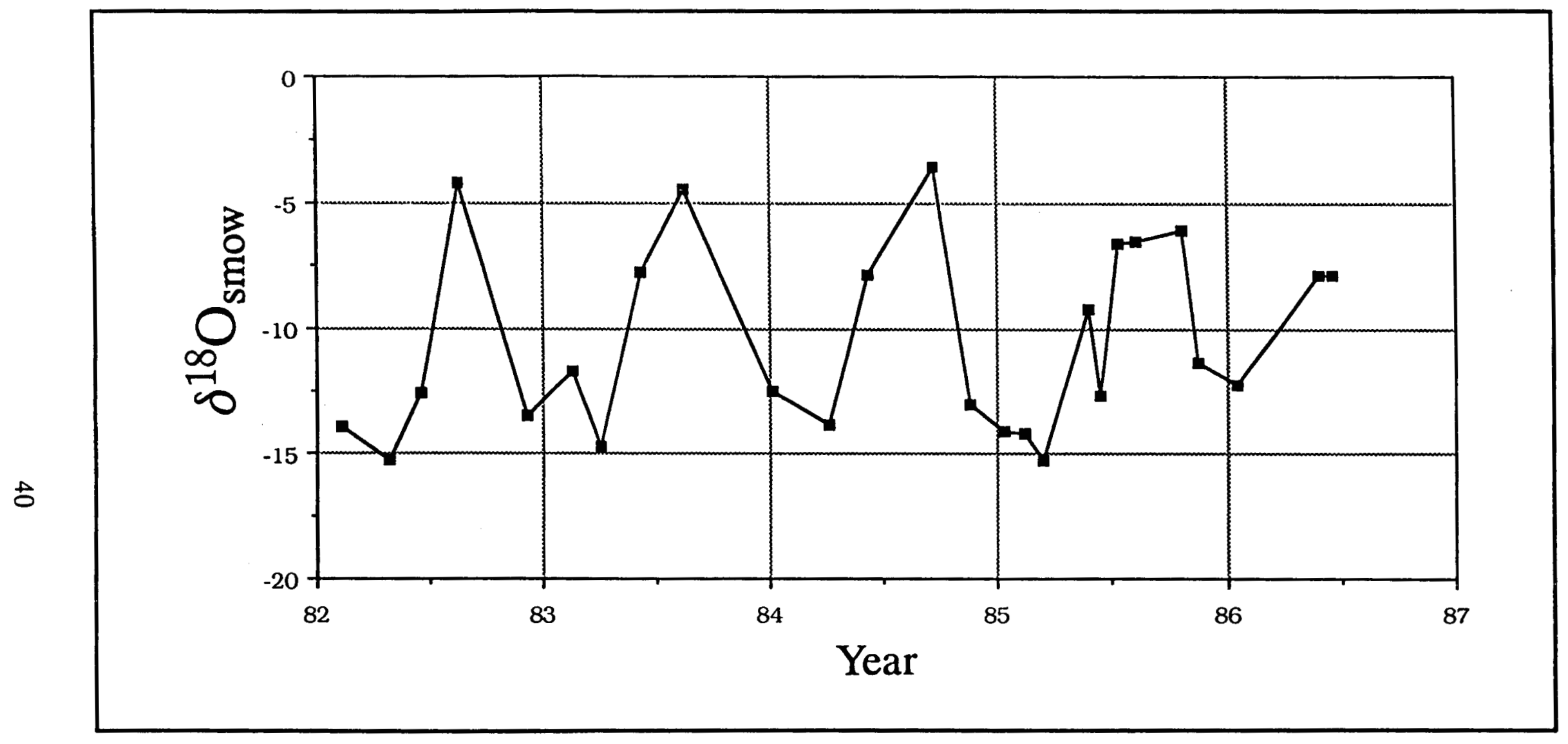

FIGURE 33. Time Series of the Weighted Average of the Oxygen Isotope Composition of Precipitation from Site TT3 During the Period of Collection. 


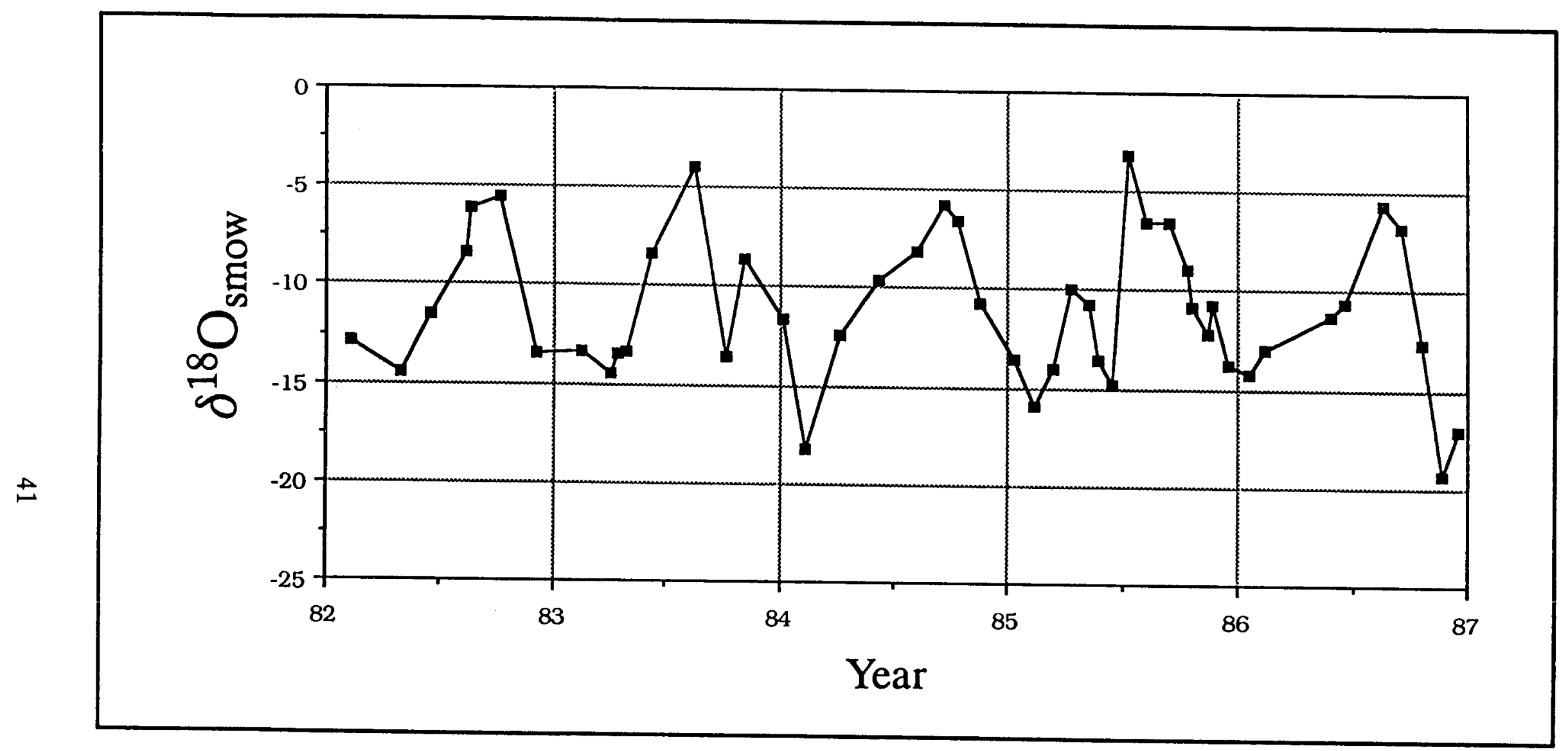

FIGURE 34. Weighted Average of $\delta^{18} \mathrm{D}$ in Precipitation from all Sites During the Period of Collection. 


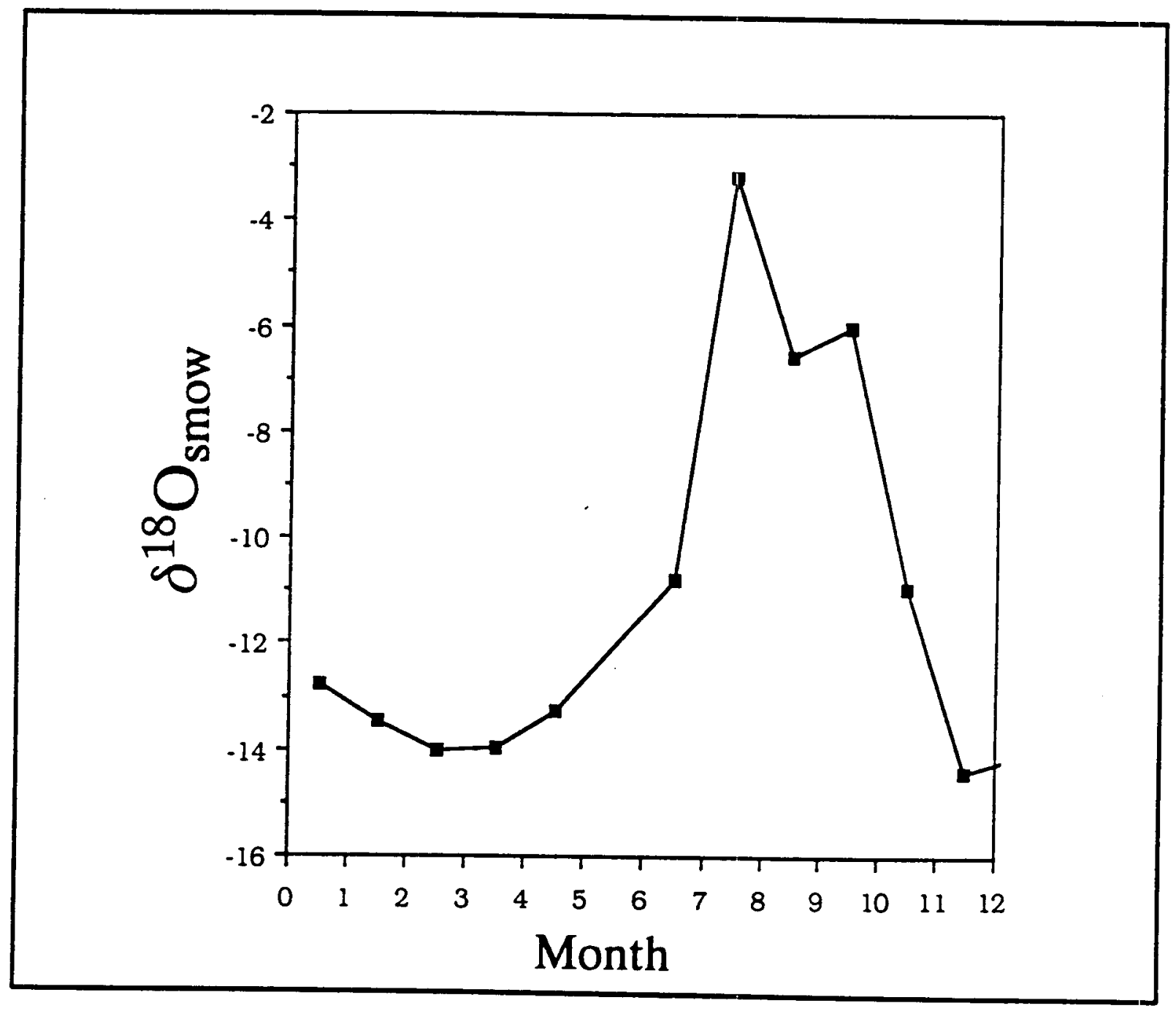

FIGURE 35. The Weighted Average of the $\delta^{18} \mathrm{O}$ of Precipitation for each Month from all Stations. 


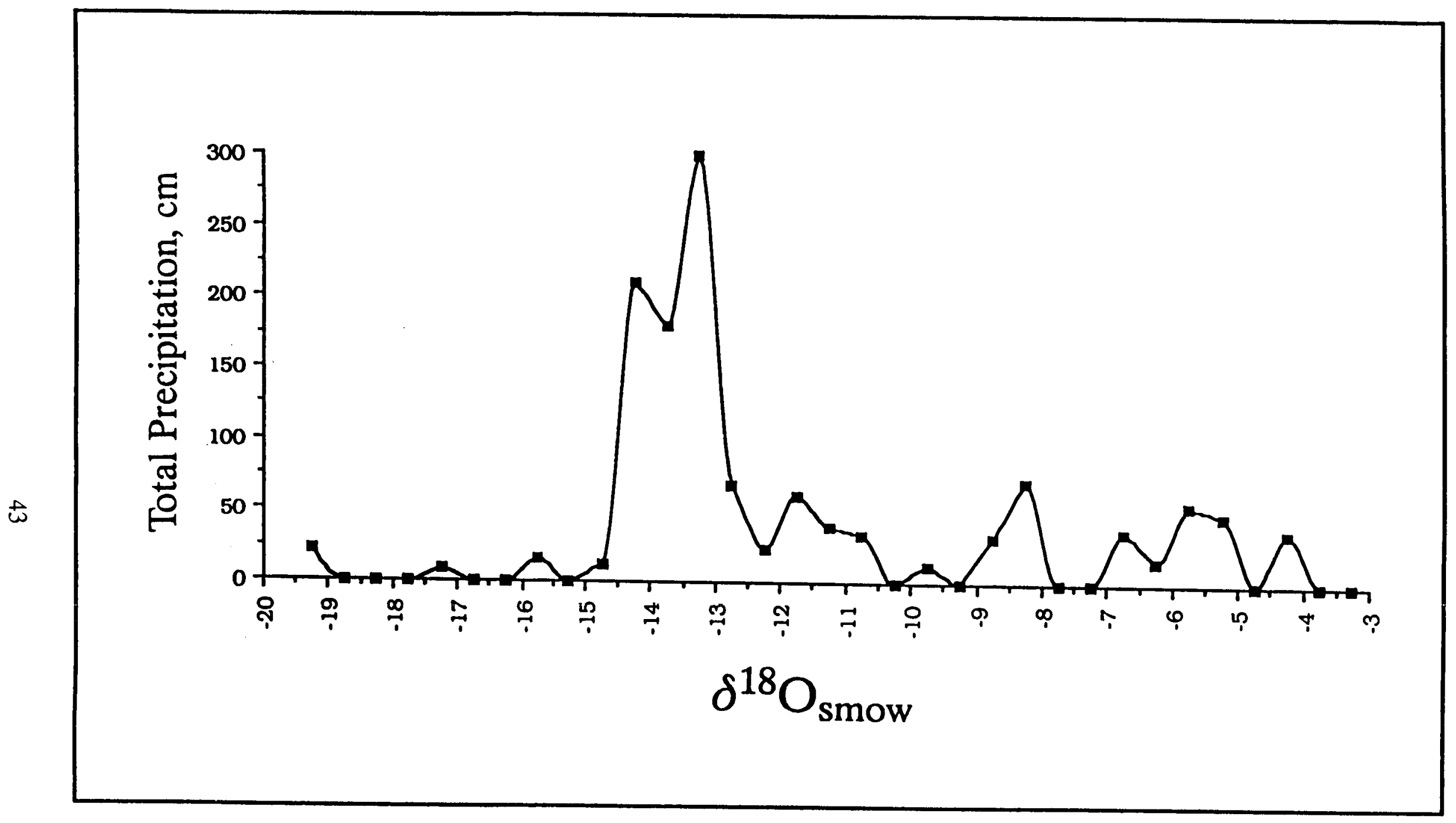

FIGURE 36. The Total Amount of Precipitation Collected within each 0.5 per mil Interval in $\delta^{18} \mathrm{O}$. The Weighted Mean of the Oxygen Isotope Compositions of all Precipitation Samples Collected is -11.9 per mil, while the Mode is between -13.0 and -14.5 per mil. 


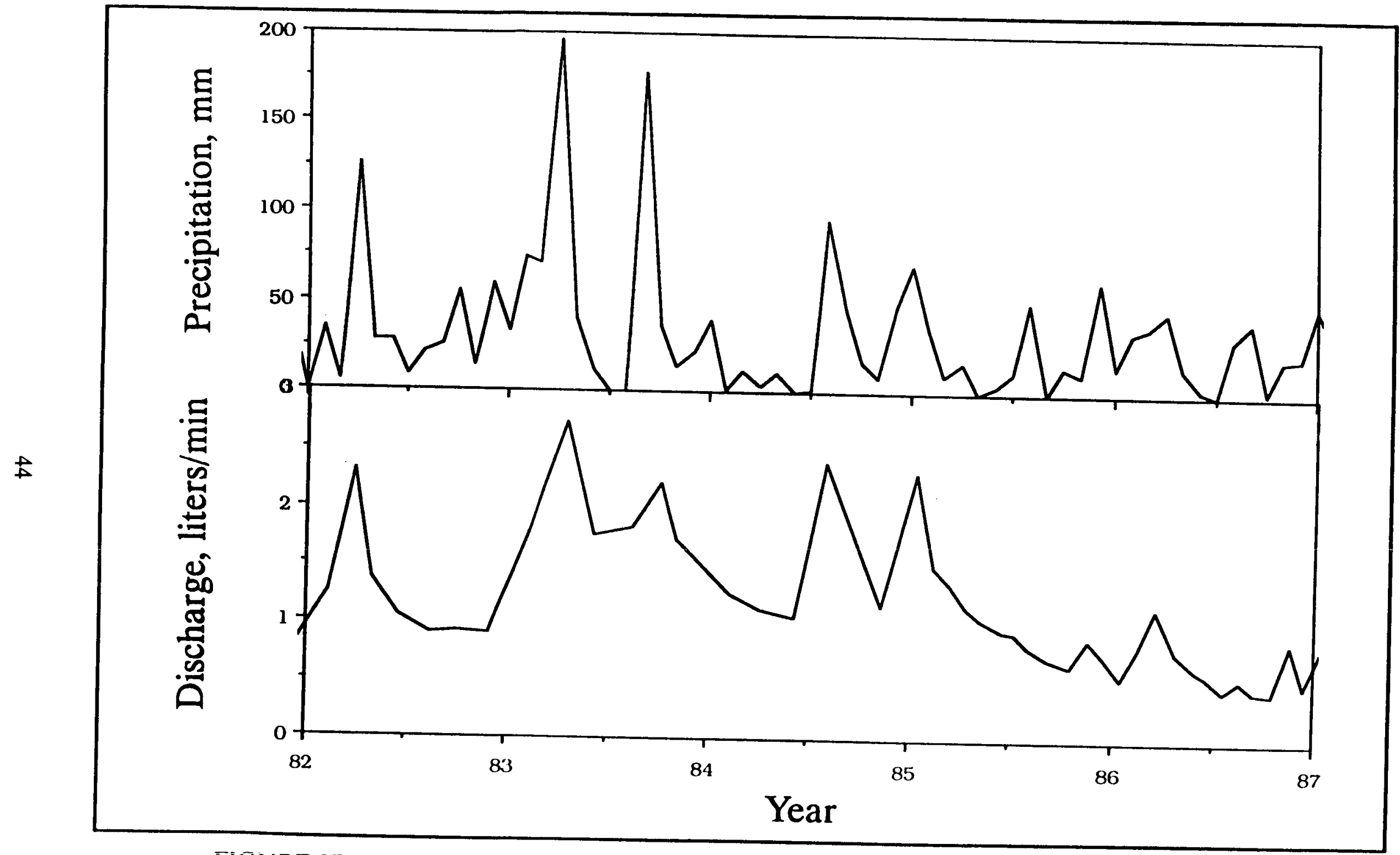

FIGURE 37. Discharges (in liters/min) from Whiterock Spring and Amounts of Precipitation (in mm) Collected Nearby. 


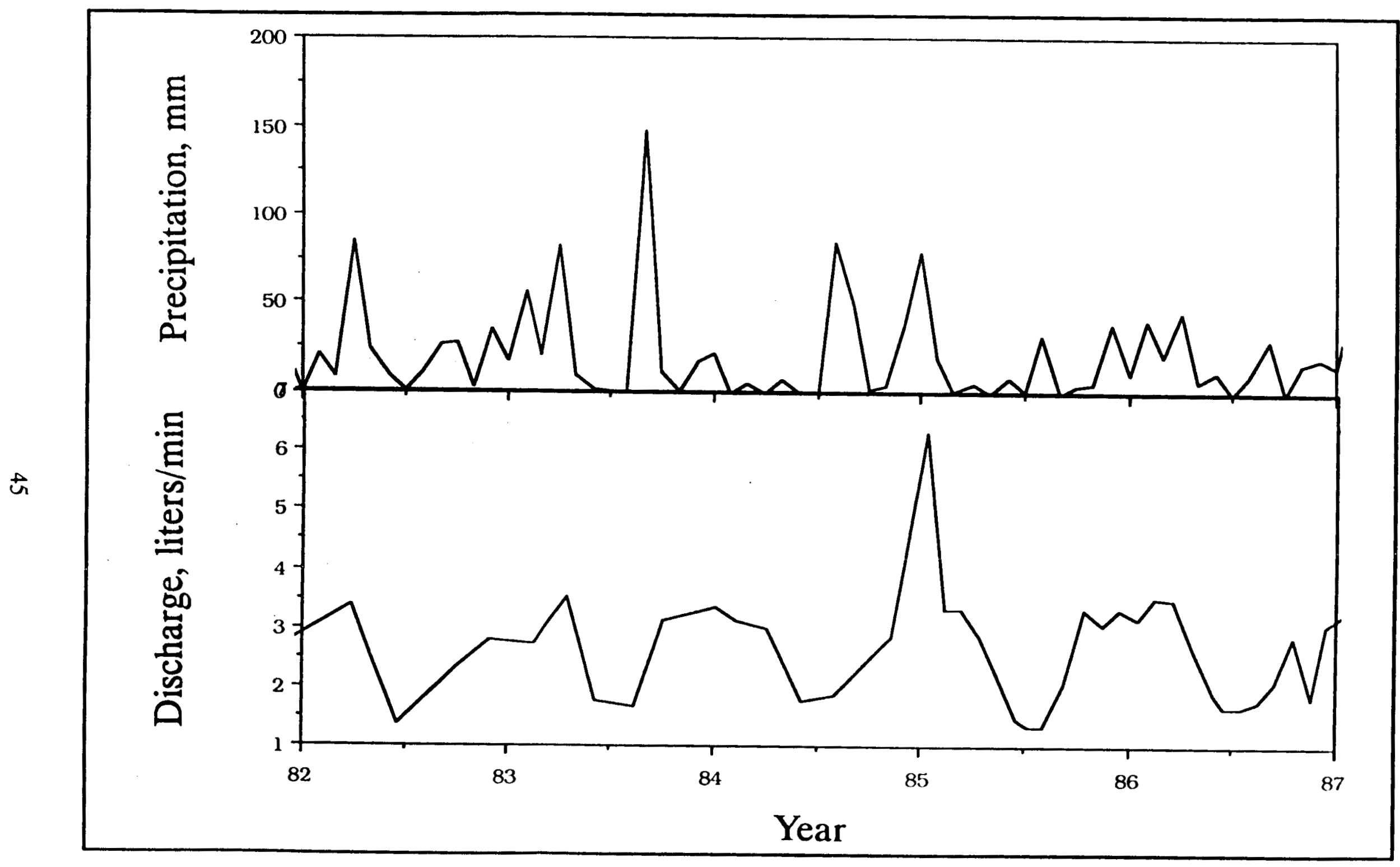

FiGuRE 38. Discharges (in liters/min) from Cane Spring and Amounts of Precipitation (in mm) Collected Nearby. 


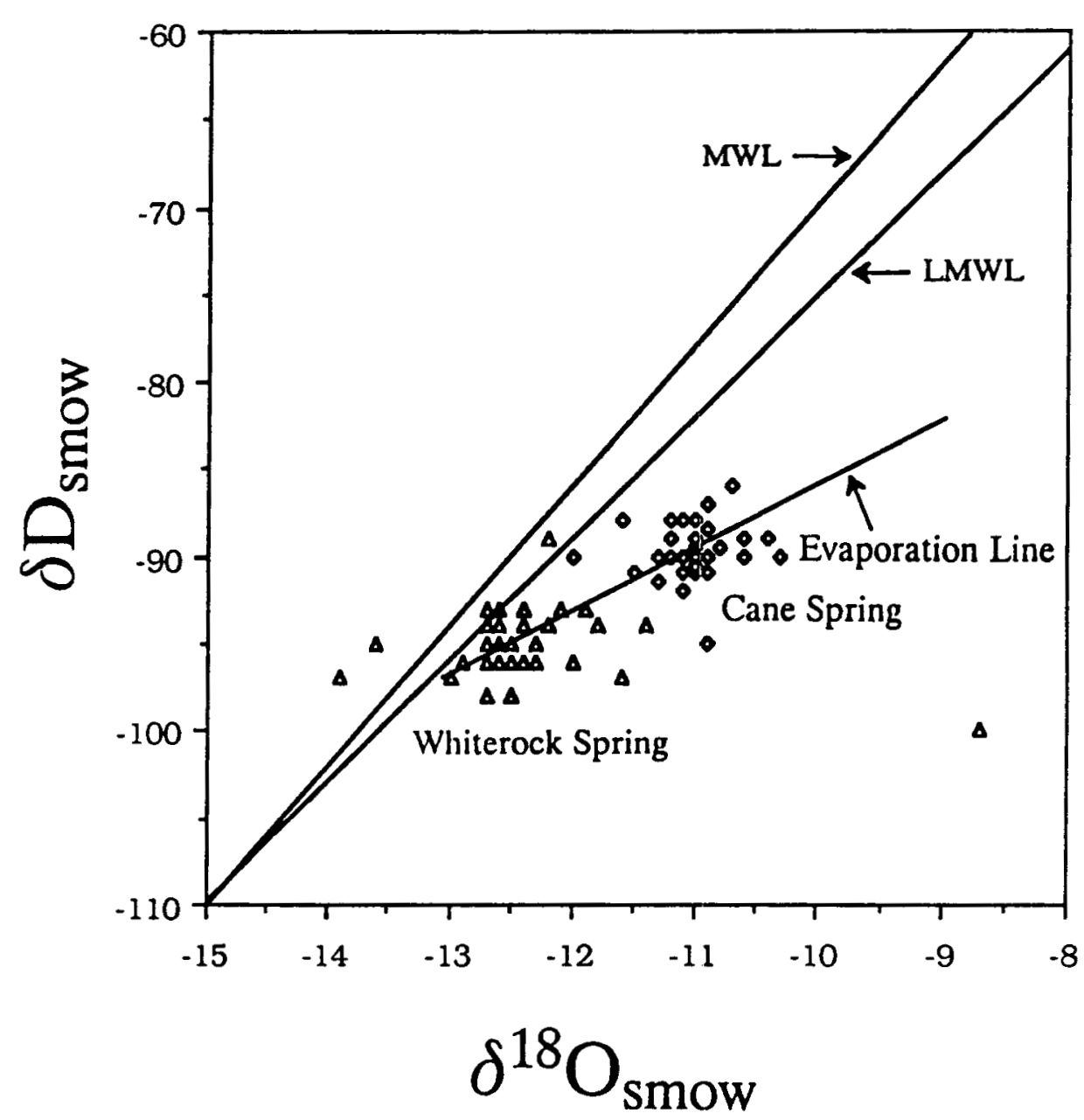

FIGURE 39. The Available Stable Isotopic Pairs $\left(\delta D\right.$ and $\left.\delta^{18} \mathrm{O}\right)$ of Discharge Water from Whiterock Spring and Cane Spring. Also shown are the Meteoric Water Line (MWL: $\delta D=8 \delta^{18} \mathrm{O}+10$; Craig, 1961) and the Local Meteoric Water Line (LMWL: $\delta D=6.87 \delta^{18} \mathrm{O}-6.5$ ) of this Research. The Spring Waters Plot in Two Separate Fields and Appear to have Undergone Evaporation following an Evaporation Line as shown. 


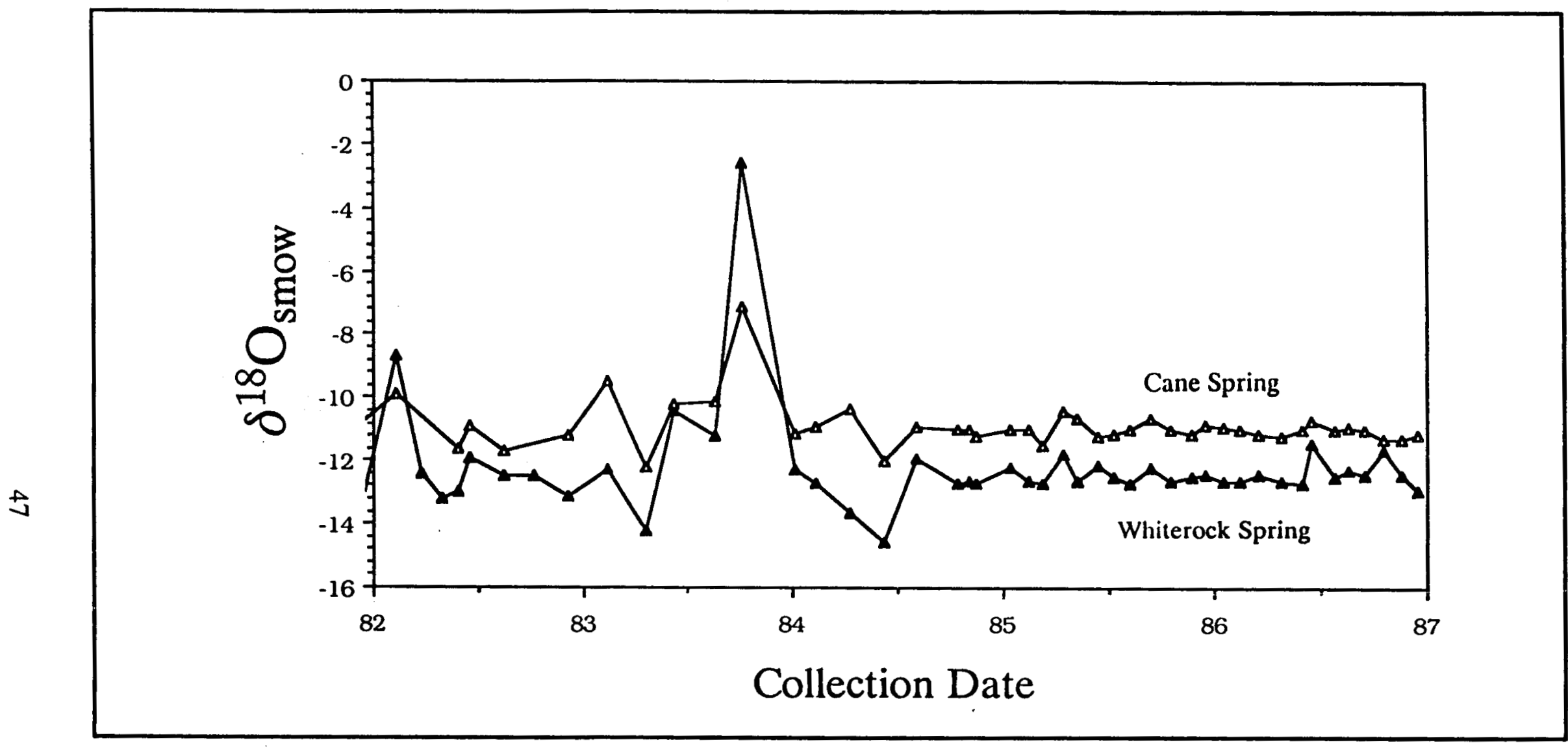

FIGURE 40. Time Series of the Stable Oxygen Isotope Compositions of Discharge Water from Cane and Whiterock Springs, for the Period of Collection. Both Springs show Considerable Fluctuation, but Display the Fluctuation in Unison. 


\section{DISCUSSION}

The stable oxygen isotopic composition of summer and winter precipitation is observed to differ by about 13 per mil, which represents differences in storm origin, history, and temperature between the seasons. In addition, occasional large summer precipitation events enriched in ${ }^{18} \mathrm{O}$ are observed. These seasonal variations and the occasional events allow the stable isotopic ratios of spring discharge to be studied in terms of infiltration and recharge.

\section{$\delta^{18} \mathrm{O}$ of Spring Discharge and Source Water}

Discharge water from Cane Spring, and to a lesser extent that from Whiterock Spring (Figure 39), has undergone evaporation and associated isotopic enrichment. The samples fall along an evaporation line (drawn by eye) that intersects the local meteoric water line at a $\delta^{18} \mathrm{O}$ value of a little less than -13 per mil. The two springs do not have the same recharge areas, and may not be produced by precipitation of the same isotopic ratio. Nevertheless, a $\delta^{18} \mathrm{O}$ value of about -13 per mil represents a reasonable value for recharging precipitation, but requires a total of 0.5 per mil enrichment by evaporation for water discharging at Whiterock Spring, and a 2 per mil enrichment for water discharging at Cane Spring. Most of the isotopic enrichment by evaporation is thought to occur at the discharge point in the adits, but some evaporation may be occurring in precipitation prior to infiltration.

\section{Relationship Between Precipitation and Spring Discharge}

The precipitation collection sites RT2 and RT3 are close to Whiterock Spring and are thought to collect precipitation representing the pre-evaporated water recharging the spring. Similarly, ST3 and ST4 are thought to collect precipitation representative of preevaporated water recharging Cane Spring. The stable oxygen isotopic compositions of discharge water from Whiterock and Cane Springs are shown over the period of sampling in Figures 41 and 42, respectively, along with the oxygen isotopic composition of precipitation for the same period of record from the nearest collection sites for each spring (RT2 and RT3 for Whiterock Spring, and ST3 and ST4 for Cane Spring).

For the first 2.5 years of record, between 1982 and mid-1984, there appears to be a good correlation between the $\delta^{18} \mathrm{O}$ of precipitation and the $\delta^{18} \mathrm{O}$ of discharge of Whiterock Spring with a time lag of about 2 to 3 months, as shown in Figure 41. This is especially apparent in the stable isotopic record during 1983, when Whiterock Spring responded isotopically to the enriched nature of a large (see Figure 37) summer precipitation event. After mid-1984, however, the $\delta^{18} \mathrm{O}$ of discharge from Whiterock Spring does not appear 


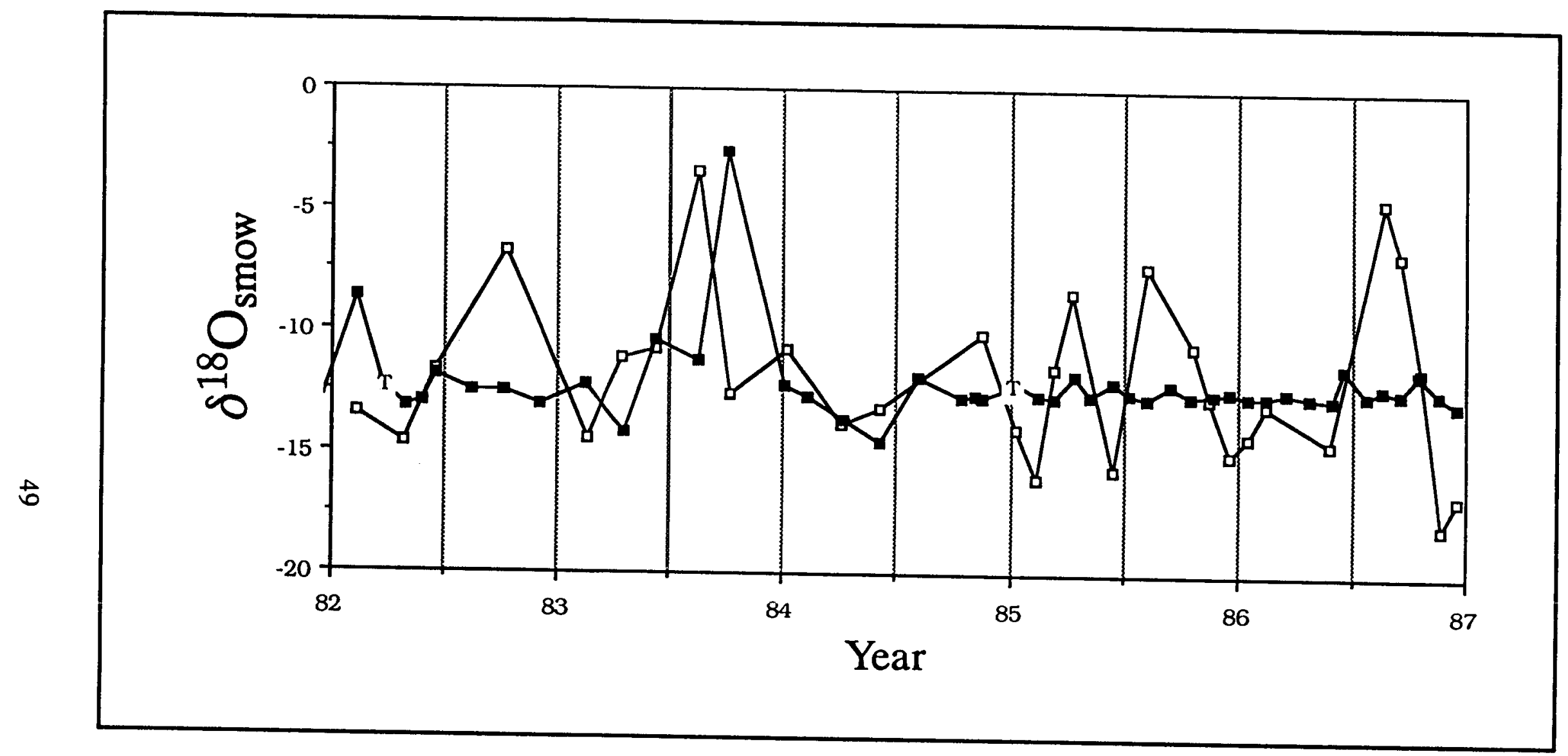

FIGURE 41. Time Series of the Stable Oxygen Isotope Compositions of Discharge Water from Whiterock Spring (closed squares) and those of the Nearest Precipitation Collection Sites (RT2 and RT3) (open squares) over the Period of Collection. The Samples also Analyzed for Tritium are Designated with a T. 
to be affected by large fluctuations in the $\delta^{18} \mathrm{O}$ of precipitation. Cane Spring (Figure 42) shows similar relationships between the $\delta^{18} \mathrm{O}$ of local precipitation and the $\delta^{18} \mathrm{O}$ of spring discharge during 1982 and 1983, although the relationship is not as direct as for Whiterock Spring. Nevertheless, this is especially notable considering the apparent age ( $\sim 600$ years) of the Cane Spring waters. Since 1984, however, the $\delta^{18} \mathrm{O}$ of Cane Spring, as with Whiterock Spring, does not appear to be affected by large fluctuations in the $\delta^{18} \mathrm{O}$ of precipitation.

During the period of collection before 1984, Whiterock Spring appeared to be in fairly direct isotopic and hydrologic (Figures 37 and 41) connection with precipitation, and to a lesser extent so did Cane Spring (Figures 38 and 42). However, after 1984, the $\delta^{18} \mathrm{O}$ of precipitation continued to fluctuate, but the $\delta^{18} \mathrm{O}$ of the discharge of the two springs did not respond. The three-year period after 1984 is characterized by more moderate precipitation amounts. From 1984 through 1987, the precipitation peaks were fewer and not as extreme, and the troughs were not as prolonged. This observation indicates that the water of large precipitation events of unique isotopic compositions may be observed in spring discharge, but a unique isotopic composition of precipitation alone is not enough to alter the stable isotopic composition of that discharge.

This conclusion requires that large precipitation events must infiltrate rapidly and flush through the hydrologic system without extensive mixing with the perched groundwater, thus allowing spring discharge to more closely reflect the stable isotopic composition of the infiltrate. However, in the absence of large precipitation events, the residence time of the recharging water increases, and affords more complete mixing of the precipitation inputs which produces a more isotopically homogenized discharge at the spring. This "short-circuiting" of the perched water table by infiltrate from large precipitation events may be explained by the nature of water movement in the unsaturated zone.

\section{Matric vs. Fracture Infiltration}

Fluid flow in unsaturated fractured rock involves two mechanisms, slow flow through matrix blocks and rapid flow through intervening fractures. Both mechanisms appear to be important in a similar environment at Yucca Mountain in southern Nevada (Sinnock et al. (1987). These researchers proposed that under low water flux (small amounts of infiltration), the flow will be exclusively matrix flow and travel times will be long. As the flux increases, permeability of the fractures increases much more rapidly than for the matrix and water will move by both matrix and fracture flow. Montazer and Wilson (1984) suggest that this process may be complicated by air being trapped in the pores during the 


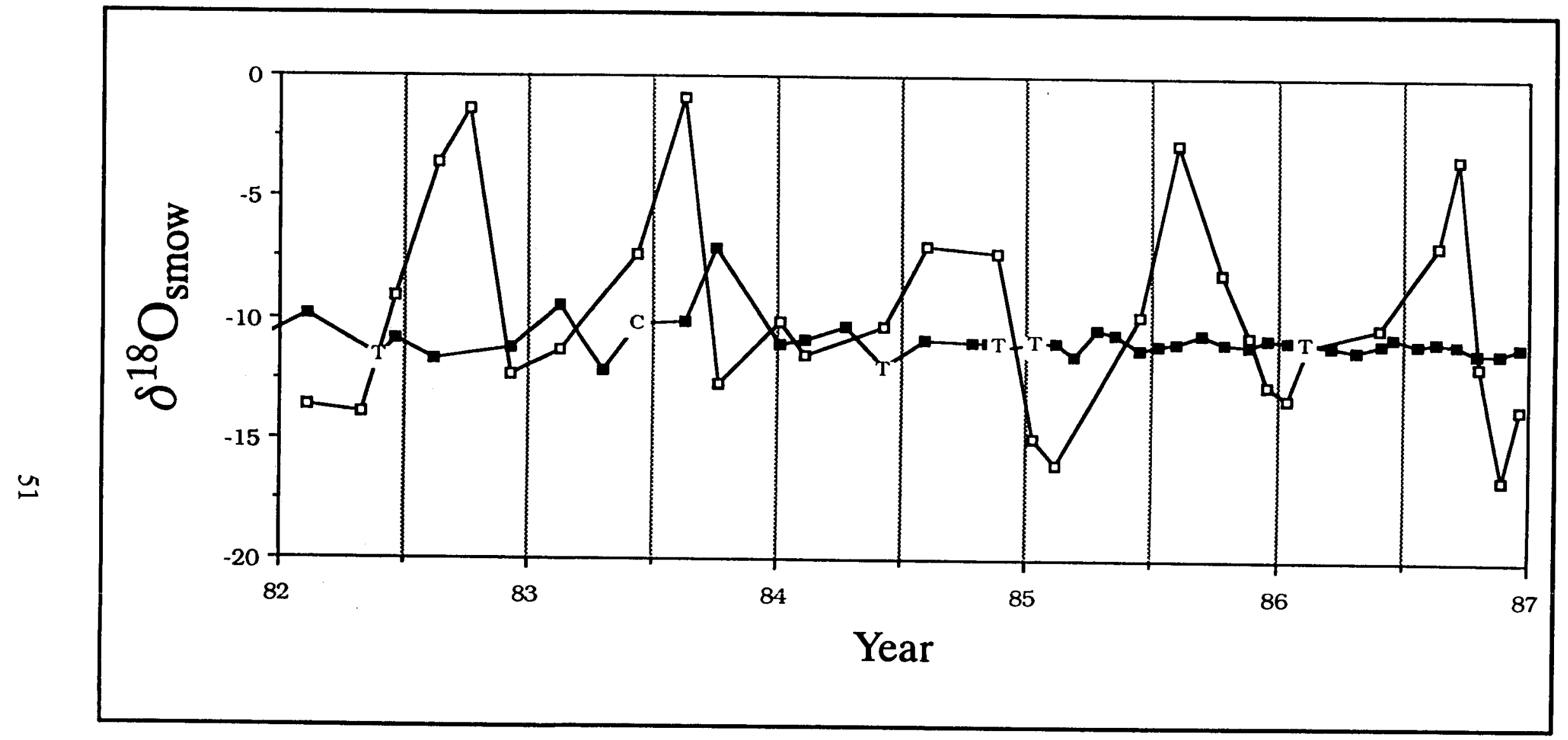

FIGURE 42. Time Series of the Stable Oxygen Isotope Compositions of Discharge Water from Cane Spring (closed squares) and those of the Nearest Precipitation Collection Sites (ST3 and ST4) (open squares) over the Period of Collection. The Samples also Analyzed for Tritium are Designated with a T, while that Analyzed for ${ }^{14} \mathrm{C}$ is Designated with a $\mathrm{C}$. 
wetting phase, and that fracture flow may dominate much earlier due to the longer time of matrix wetting. The magnitude of the effects depends upon the rate at which water is introduced into the system and appears to be greatest for large precipitation events after prolonged dry spells. After large summer storm events, conditions may favor infiltration by fracture flow allowing the water a short-circuit path to the springs, thus affording little mixing with the matrix infiltrate.

\section{Seasonal Effects and the $\delta^{18} \mathrm{O}$ of Spring Discharge}

The oxygen isotopic ratios of the homogenized discharge water from Whiterock Spring (as well as for Cane Spring), as observed between 1984 and 1987 as shown in Figure 41 (Figure 42), may have, prior to isotopic enrichment by evaporation, represerted the ratio of recharge between enriched summer and depleted winter precipitation. The estimated oxygen isotopic composition of pre-evaporated recharge water to Whiterock Spring $\left({ }^{18} \mathrm{O}=-13\right.$ per mil) is more enriched than the winter mode of between -13 and -14.5 per mil (Figure 36). However, it is more depleted than the weighted mean of all precipitation samples collected $\left(\delta^{18} \mathrm{O}=-11.9\right.$ per mil). As observed during the large summer precipitation event of 1983 , the springs do respond isotopically (and hydrologically) to enriched summer precipitation, indicating that, at least under some conditions, summer precipitation is responsible for some infiltration.

Since large summer precipitation events with enriched stable isotopic ratios effect large spring discharges reflecting the enriched nature of the precipitation, summer precipitation cannot be discounted as supplying water to the isotopically homogenized groundwater. Thus, it is thought that both summer and winter precipitation is responsible for recharging the groundwater. However, for summer precipitation, recharge may only be accomplished by large precipitation events, some of which short-circuit the perched water table.

\section{SUMMARY AND CONCLUSIONS}

Precipitation samples alone cannot yield information concerning the hydrogeology of a particular region. However, the stable isotopic composition of the samples, as collected, yields valuable information about the average stable isotopic composition of precipitation on the NTS. This data is the "input signal" for the infiltration of precipitation, thus the information will be of utmost importance in attempting to determine recharge locations and rates.

The substantial and predictable difference in the oxygen isotopic ratios between summer and winter precipitation may allow the determination of the season and type of 
precipitation conducive to infiltration. In addition, the long-term average of the oxygen isotopic composition of present-day precipitation may aid in the identification of groundwaters of past climates as well as aid in determining the conditions of those climates.

The total average difference in $\delta^{18} \mathrm{O}$ of precipitation for a five-year period in southern Nevada amounted to only 2.3 per mil year to year, while differences based on location were only 3.7 per mil. The largest difference was between enriched summer and depleted winter precipitation and amounted to more than 13 per mil. In addition, several large summer precipitation events of enriched isotopic composition were observed. This seasonal difference, and those of the large events, were compared to the $\delta^{18} \mathrm{O}$ of discharge of two springs issuing from perched water tables.

During the first 2 to 2.5 years of collection, the springs responded in both volume and $\delta^{18} \mathrm{O}$ of discharge to large precipitation events. However, during the last 2 to 2.5 years of collection, when precipitation moderated in amounts but not stable isotopic composition, the springs displayed not only less variation in discharge, but in stable isotopic composition as well. 


\section{REFERENCES}

Bigeleisen, J., M.L. Perlman and H. Prosser, 1952. Conversion of hydrogenic materials to hydrogen for isotopic analysis. Anal. Chem., 24: 1356-1357.

Craig, H., 1961. Isotope variations in meteoric waters. Science, 133: 1702-1703.

Darling, W.G. and A.H. Bath, 1988. A stable isotope study of recharge processes in the English Chalk. Jour. of Hydrology 101: 31-46.

Dugan, J.P. Jr., J. Borthwick, R.S. Harmon, M.A. Gagnier, J.E. Gahn, E.P. Kinsel, S. Macleod, J.A. Viglino and J.W. Hess, 1985. Guanidine hydrochloride method for determination of water oxygen isotope ratios and the ${ }^{18} \mathrm{O}$ fractionation between carbon dioxide and water at $25^{\circ} \mathrm{C}$. Anal. Chem., 57: 1734-1736.

French, R.H., 1985. Daily, seasonal and annual precipitation at the Nevada Test Site, Nevada, Desert Research Institute, University of Nevada, Publication No. 45042.

French, R.H., 1983. A preliminary analysis of precipitation in southern Nevada. Desert Research Institute, University of Nevada, Publication No. 45031.

Hales, J.E. Jr., 1974. Southern United States Summer Monsoon Source -- Gulf of Mexico or Pacific Ocean. Journal of Applied Meteorology, 13: 331-342.

Hales, J.E. Jr., 1972. Surges of maritime tropical air northward over the Gulf of California. Monthly Weather Review, 100(4): 298-306.

Hershey, R.L., B.F. Lyles and J.W. Hess, 1987. Hydrologic and hydrochemical investigation of the Spring Mountains, Clark County, Nevada. Geological Society of America, Abstracts with Programs, Vol. 19, No. 7, p. 701.

Ingraham, N.L. and B.E. Taylor. Light Stable Isotope Systematics of Large-Scale Hydrologic Regimes in California and Nevada. In Prep.

Milne, W.K., L.V. Benson and P.W. McKinley, 1987. Isotope content and temperature of precipitation in Southern Nevada, August 1983 - August 1986. USGS Open-File Report 87-463.

Montazer, P. and W.E. Wilson, 1984. Conceptual Hydrologic Model of Flow in the Unsaturated Zone, Yucca Mountain, Nevada. USGS Water Resources Investigations Report: 84-4345.

Simpson, E.S., D.B. Thorud and I. Friedman, 1972. Distinguishing seasonal recharge to groundwater by deuterium analysis in southern Arizona, Proceedings Reeding Symposium, International Association of Science Hydrology, 113-121.

Sinnock, S., Y.T. Lin and J.P. Brannen, 1987. Preliminary Bounds on the Expected Postclosure Performance of the Yucca Mountain Repository Site, Southern Nevada. JGR 92: 7820-7842. 
Smith, G.I., I. Friedman, H. Klieforth and K. Hardcastle, 1979. Areal distribution of cleuterium in eastern California precipitation, 1968-1969. Jour. of Applied Meteorology, 18: $172-188$.

Thordarson, W., 1965. Perched groundwater in zeolitized-bedded tuff, Rainier Mesa and vicinity, Nevada Test Site, Nevada. USGS TEI-862.

Winograd, I.J. and A.C. Riggs, 1984. Recharge to the Spring Mountains, Nevada: Isotopic Evidence. Geological Society of America, Abstracts with Programs, Vol. 16, p. 698. 